IZA DP No. 6636

Frictions and the Joint Behavior of Hiring and Investment

Eran Yashiv

June 2012 


\title{
Frictions and the Joint Behavior of Hiring and Investment
}

\author{
Eran Yashiv \\ Tel Aviv University \\ and IZA
}
Discussion Paper No. 6636
June 2012

\author{
IZA \\ P.O. Box 7240 \\ 53072 Bonn \\ Germany \\ Phone: +49-228-3894-0 \\ Fax: +49-228-3894-180 \\ E-mail: iza@iza.org
}

\begin{abstract}
Any opinions expressed here are those of the author(s) and not those of IZA. Research published in this series may include views on policy, but the institute itself takes no institutional policy positions.

The Institute for the Study of Labor (IZA) in Bonn is a local and virtual international research center and a place of communication between science, politics and business. IZA is an independent nonprofit organization supported by Deutsche Post Foundation. The center is associated with the University of Bonn and offers a stimulating research environment through its international network, workshops and conferences, data service, project support, research visits and doctoral program. IZA engages in (i) original and internationally competitive research in all fields of labor economics, (ii) development of policy concepts, and (iii) dissemination of research results and concepts to the interested public.
\end{abstract}

IZA Discussion Papers often represent preliminary work and are circulated to encourage discussion. Citation of such a paper should account for its provisional character. A revised version may be available directly from the author. 


\begin{abstract}
Frictions and the Joint Behavior of Hiring and Investment

The decisions of firms on investment and hiring play a crucial role in business cycle fluctuations. This paper explores their dynamic behavior in the presence of frictions. It does so within a unified framework, stressing their mutual dependence and placing the emphasis on their joint, forward-looking behavior. Using estimation of aggregate, private sector U.S. data, it shows that the model with frictions is able to fit the data. A key element is the interaction of hiring and investment costs. It is significant and negatively signed, implying complementarity between investment and hiring. There is a substantial role for aggregate labor market conditions in hiring costs, whereby the latter are lower in "good times." The fit of the investment part of the model is poor if hiring is left out completely or is introduced without the interaction between the two. The results capture the not so-well known fact whereby there is negative co-movement of gross investment and gross hiring, the former being procyclical while the latter is counter-cyclical. This is so as they follow the cyclical behavior of their respective present values. The relevant intertemporal considerations are highlighted. An asset-pricing type empirical analysis of the estimation results indicates that the hiring rate depends mostly on future labor profitability while the investment rate depends mostly on future returns.
\end{abstract}

JEL Classification: E24, J23, J63, J64

Keywords: gross investment, gross hiring, frictions, business cycles, present values of hiring and investment, forward-looking behavior, production-based asset pricing, complementarities, labor market conditions

Corresponding author:

Eran Yashiv

Naftali 052

Tel Aviv University

Tel Aviv 69978

Israel

E-mail: yashiv@post.tau.ac.il 


\section{Frictions and the Joint Behavior of Hiring and Investment ${ }^{1}$}

\section{Introduction}

This paper studies the joint behavior of hiring and investment in the presence of frictions, using private sector U.S. data. The importance of these decisions by firms for aggregate activity cannot be overstated. The evolution of employment and of the capital stock are essential for the understanding of macroeconomic fluctuations. Search and matching models have shown that gross hiring is a key factor for understanding employment and unemployment dynamics. ${ }^{2}$ Hiring frictions were shown to play a key role in determining the business cycle properties of labor productivity. ${ }^{3}$ Investment is key for the understanding of the evolution of the capital stock and consequently of firm market value. ${ }^{4}$

Hiring and investment are modelled in the literature as the outcomes of a dynamic, intertemporal optimization problem of the firm. The intertemporal dimension rests on the existence of frictions, whereby the firm incurs costs and time lags to turn capital and labor into active factors of production. But while the firm evidently decides on both hiring and investment, the treatment in much of the literature has either focused on the behavior of one and not the other, or has posited costs pertaining to one but not the other. Additionally, part of the literature has been concerned with the narrower concept of adjustment costs, which typically relate to net hiring rather than gross hiring (hugely different variables) or which do not cater for job-worker matching processes. Thus, the search and matching literature focuses on job vacancy costs and posits either no capital or costless investment in capital. Investment costs models follow the same route with respect to capital, usually disregarding labor. Even DSGE models,${ }^{5}$ usually model frictions with respect to only one factor - capital or labor. Moreover, all too often, the empirical macroeconomic work that has estimated costs,

\footnotetext{
${ }^{1}$ I thank Russell Cooper, Jordi Gali, Giuseppe Moscarini, Richard Rogerson, Gianluca Violante, seminar participants at various conferences - the NBER Summer Institute, Rogerson, Shimer and Wright EF group meeting; CEPR ESSIM meetings; LMDG meeting (Sandbjerg, Denmark); and the Fundacion Rafael del Pino (Madrid), and at Tel Aviv University, CREI (Pompeu Fabra), EUI (Florence), Bristol, the Bank of England, and Birbeck College (London) for helpful comments on previous versions, and Ofer Cornfeld, Darina Waisman and especially Tanya Baron for excellent research assistance. All errors are my own.

${ }^{2}$ See, for example, Hall (2007) and Rogerson and Shimer (2011).

${ }^{3}$ Gali and van Rens (2010) show that a lower degree of hiring frictions may lower the cyclicality of labor productivity in ways which are consistent with actual U.S. aggregate data dynamics.

${ }^{4}$ See Erickson and Whited (2000), Bond and van Reenen (2007), Liu, Whited and Zhang (2009) and Cochrane (2011).

${ }^{5}$ Such as those by Christiano, Eichenbaum and Evans (2005), Smets and Wouters (2007), or Gali $(2008,2010)$.
} 
especially investment costs, has reported weak results. This weakness was manifested in a lack of fit or the need to postulate implausibly large costs to explain the data.

This paper explores the dynamic behavior of investment and hiring within a unified framework, stressing their mutual dependence and placing the emphasis on their joint, forward-looking behavior. Using structural estimation of the firms' optimality equations in aggregate, private sector U.S. data, it shows that it is able to explain the negative co-movement of investment and hiring and their different cyclical properties. The frictions modelled pertain to time lags, to gross rather than net flows, cater for the interaction of hiring and investment costs, and capture matching frictions by allowing for labor market conditions to affect costs. In particular, estimation results explain the (not so-well known) fact that while gross investment is pro-cyclical, gross hiring is counter-cyclical. In doing so, it shows that costs matter for both capital and labor, that the interaction between them is important, and that the model is able to fit the data without implying a high degree of frictions. It also indicates that labor market conditions matter for the behavior of costs on both investment and hiring. The paper shows what is lacking (empirically) when one does not cater for these features. These findings have implications for business cycle modelling, such as the advantages of incorporating joint investment and hiring costs, complete with the cited interaction and role for labor market conditions, into DSGE models.

A major implication of the findings is that hiring and investment can be treated as forward-looking variables, reflecting the expectations of future discounted profits from employing labor and capital. This naturally links up with stock prices that are also forward-looking and relate to the same expected discounted future profits. Indeed, in previous work, Monika Merz and I (Merz and Yashiv (2007)) have shown that this set-up allows one to define asset values for hiring and for investment and that these values can be used to explain the time variation of equity values of firms in the U.S. economy. ${ }^{6}$ The current paper retains the focus on forward-looking behavior but does not make use of stock market data or try to explain them. Rather, it aims at the empirical characterization of hiring and investment themselves as forward-looking decisions. Using the estimation results, it employs a number of techniques used in the asset pricing literature (forecasting regressions, restricted VAR analyses and variance decompositions) to study this forward-looking aspect. The analysis suggests that investment and hiring are differentially related to their expected, future determinants. Investment is linked more to movements in future returns than to changes

\footnotetext{
${ }^{6}$ Building on Merz and Yashiv (2007), Bazdresch, Belo and Lin (2009) have further shown that hiring and investment predict stock returns in a cross-section of U.S. publicly traded firms.
} 
in the marginal product of capital. Hiring is linked more to changes in labor profitability (the marginal product less the wage) and less to the movements in future returns. In particular, in recessions, higher expected future profitability from labor leads firms to increase the rate at which they hire workers, though the employment stock and worker job-finding rates decline.

The paper proceeds as follows: Section 2 presents the business cycle facts of investment and hiring in the U.S. economy, highlighting their differential behavior. Section 3 briefly discusses the relevant related strands of literature. Section 4 presents the firm's optimization problem and the resulting optimality conditions. Section 5 discusses estimation issues and presents the results. Section 6 uses the results to look at the implied magnitude of frictions and to gauge the plausibility of the estimates. Section 7 uses the estimates to approximate the present value relationships embodied in the model and analyze the links of hiring and investment with the variables affecting them in the future. Section 8 explores the implications of all the preceding results for the co-movement and cyclical behavior of hiring and investment. Section 9 concludes. Technical matters and data issues are treated in the appendices.

\section{Business Cycle Facts}

The analysis below focuses on the gross hiring rate $\frac{h}{n}$ and the gross investment rate $\frac{i}{k}$ of the aggregate U.S. economy. Figure 1 plots these series. ${ }^{7}$ The figure has four panels. Figure 1a shows the raw series. Figures $1 \mathrm{~b}$ and $1 \mathrm{c}$ show, in two panels each, the logged series in levels and in Hodrick-Prescott (HP) and Band Pass (BP) filter terms, together with NBER-dated recessions. Figure 1d shows in two panels the logged, HP-filtered and BP-filtered series of investment and hiring with the NBER-dated recessions.

\section{Figure 1}

Inspection of the figures reveals that the investment and hiring rates series do not move together and have markedly different cyclical behavior investment is pro-cyclical while hiring is counter-cyclical.

Table 1 provides a quantitative summary of these features. It looks at the stochastic behavior of investment and hiring rates in logged, HPfilter terms and BP-filter terms. It presents co-movement statistics, the dynamic correlations of investment and hiring and their co-movement with three cyclical measures (real business sector GDP $f$, labor productivity $\frac{f}{n}$ and capital productivity $\frac{f}{k}$ ).

\section{Table 1}

\footnotetext{
${ }^{7}$ The data are further discussed in Section 4.2 below.
} 
Gross hiring and gross investment rates exhibit negative correlation, contemporaneously and at some leads and lags. Both contemporaneously and dynamically, hiring is counter-cyclical with respect to the three cyclical variables. These correlations are stronger when using the BP filter, relative to the HP filter. With respect to the same cyclical measures, investment is pro-cyclical, sometimes strongly so. This is so both contemporaneously and at some leads and lags. In this case the filtering method does not matter much.

Note that in recessions hiring rises while investment falls. Two years ahead of the recession investment rises and hiring falls; closer to the recession they switch signs. Judging by the strength of the correlation measures, investment rates are stronger leading indicators of the cycle.

The counter-cyclicality of hiring may appear counter-intuitive. To put this behavior in further perspective and show how it relates to other labor market facts, I look at labor market variables which are often discussed in the literature. Note that in steady state, hiring to employment $h$ equals separations from employment $s$ :

$$
h=s
$$

Non-employment in the steady state, i.e., unemployment $u$ plus the pool out of the labor force $o$, is given by:

$$
\frac{u+o}{p o p}=\frac{\psi}{\frac{h}{u+o}+\psi}
$$

where $p o p$ is the working age population and $\psi$ is the separation rate from employment $n(s=\psi n)$.

In steady state the hiring rate is the product of the job finding rate, steady state non-employment and the inverse of the employment rate:

$$
\frac{h}{n}=\frac{h}{u+o} \times \frac{u+o}{p o p} \times \frac{p o p}{n}
$$

Using the above formulation of steady-state non-employment:

$$
\underbrace{\frac{h}{n}}_{\text {hiring rate }}=\underbrace{\frac{h}{u+o}}_{\text {job finding }} \times \underbrace{\frac{h}{\frac{h}{u+o}+\psi}}_{\mathrm{ss} \text { non-emp }} \times \underbrace{\frac{1}{\frac{n}{p o p}}}_{\text {inv emp ratio }}
$$

Table 2 shows some of the same moments for these variables.

Table 2 
The table shows that the employment stock $n$ and the job finding rate $\frac{h_{t}}{u_{t}+o_{t}}$ are pro-cyclical, as is well known. At the same time the gross hiring rate $\frac{h_{t}}{n_{t}}$ is counter-cyclical. Steady state non-employment $\frac{\psi}{\frac{h}{u+o}+\psi}$ and the inverse of the employment ratio $\frac{1}{\frac{n}{p o p}}$ are counter-cyclical, as widely known too. The hiring rate is counter-cyclical as the counter-cyclicality of the last two variables dominates the pro-cylicality of the job-finding rate. In what follows, the gross hiring rate $\frac{h_{t}}{n_{t}}$ will be a key variable in the analysis. It is useful to keep in mind that, in line with these features, it behaves differently from the employment stock $n$ and is not to be confused with the job finding rate $\frac{h_{t}}{u_{t}+o_{t}}$.

Some of these stylized facts are not obvious. In particular, one needs to account for the fact that hiring and investment move in opposite ways. Intuitively we may think that if investment rises, hiring should rise too, at least with a lag, but this is not what we observe. Moreover, their relationship with the cycle is different and switches sign as discussed above.

Why did the literature give little, if any, attention to these facts? This is so probably because business cycle models usually do not look at the gross hiring flows, but rather at the employment stock. Search and matching models look at gross hiring flows but typically do not consider investment. Hence the two - investment and hiring - are usually not examined together. This approach is manifest in the literature review to which I turn now.

\section{Literature}

The current paper relates to two major strands in the macroeconomic literature and provides a missing link between them. It then makes use of a third strand, in Finance, which has examined the relation between present value variables and their future determinants. I examine each in turn.

The first is the literature on search and matching models, which feature dynamic, optimal hiring decisions by firms in the face of frictions (see Pissarides (2000), Rogerson, Shimer,and Wright (2005), Yashiv (2007) and Rogerson and Shimer (2011) for overviews and surveys). Hiring costs and time lags are the expression of frictions in these models, which differ from the neo-classical model mainly by the emphasis placed on the existence of such frictions in the labor market. The first order condition for optimal hiring is a key ingredient and this is one of the two estimating equations examined here. Most of this literature, however, does not include capital as a factor of production, and when it does, it is typically assumed not to be the subject of any friction. Many papers posit very simple hiring costs, usually a linear function of the number of job vacancies. Thus, it usually states that marginal vacancy costs are constant. The finding, as indicated above, is that gross hiring, subject to these frictions, is key in accounting 
for employment and unemployment dynamics. The model here features a generalization of the hiring problem and a wider concept of costs relative to what has been considered by these models.

It should also be noted that models which feature costs of adjusting labor have been studied for about half a century (Hamermesh (1993) provides a useful discussion). But most of these studies typically relate to net employment changes as distinct from gross changes of the type examined here, and have ignored any interaction with capital. The distinction between net and gross flows is critically important, as hiring costs are incurred with respect to the gross flow of incoming workers and the stochastic properties of these various flows are substantially different (see Hamermesh and Pfann (1996), in particular pp. 1266-67).

The second strand of literature includes investment models, mostly following the seminal contributions of Lucas (1967) and Lucas and Prescott (1971) and of Tobin (1969) and Brainard and Tobin (1968). ${ }^{8}$ These models have been studied extensively for over four decades. Chirinko (1993) is an earlier survey and Erickson and Whited (2000) and Bond and van Reenen (2007) are more recent discussions. The idea in these models is that costs are key to the understanding of investment behavior. As in the hiring case, they endow the investment problem with its dynamic optimization aspect and are geared to capture the real world feature of gradual adjustment of the capital stock. These models have encountered a lot of empirical difficulties and have engendered much debate (see Chirinko (1993) and Bond and van Reenen (2007)). Like search and matching models, much of this literature does not feature the other factor of production, namely labor. In the current paper I present results both from the "traditional" formulation of the investment costs model and from a formulation which allows for the interaction of investment costs and hiring costs. Hence, when presenting the results I provide a comparison with the results of nine key studies in this literature. The approach here is akin to the Euler equation approach in the investment literature proposed by Abel (1980), with the important distinction that it incorporates hiring and the interaction of costs between hiring and investment. When discussing results I note the difference between aggregate and micro-based studies. Note, too, that in what follows I do not use stock market or firm value data as investment $Q$ models do. As mentioned, the linkages with such data were explored by Merz and Yashiv (2007).

\footnotetext{
${ }^{8}$ The Lucas (1967) paper formulates adjustment costs and dynamic firm behavior. Lucas and Prescott (1971) analyze investment under uncertainty in the presence of convex costs of adjustment. The Tobin (1969) paper deals, among many other issues, with the relation of investment to stock market value and has little to say on the relevant dynamics. The link between convex costs of adjustment and the Tobin's Q theory of investment was made explicit by Mussa (1977) and by by Abel (1983). Note, though, that Q can be related to investment without any frictions; see Abel and Eberly (2010).
} 
It should also be noted that models of the business cycle (evidently) feature optimal hiring and investment decisions. Many of them do not feature frictions, though a large part of the RBC literature assumes lags in the installation of capital. More recent RBC models and the latest vintage of business cycle models, such as Christiano, Eichenbaum and Evans (2005) or Smets and Wouters (2007) do posit costs for investment but no frictions in hiring. Note, too, that in business cycle models there is no explicit interaction between hiring costs and investment costs.

A key issue in the current paper is the mutual dependence of hiring and investment and the interaction of their costs. This is not a new issue. Mortensen (1973) has examined the interrelation of costs in a theoretical model and over the years some empirical work was attempted; prominent examples include Nadiri and Rosen (1969), Shapiro (1986), Hall (2004) and Bloom (2009). These studies point to the potential importance of including costs on both capital and labor. However key differences with the current study are that these papers do not model at least one of two elements, which the empirical work below finds to be of crucial importance: (i) an interaction term between the two costs; and (ii) gross, as opposed to net, and aggregate, as opposed to micro-level, hiring flows. Hence most of their findings are quite different from what is reported here.

This paper stresses the forward-looking aspect of hiring and investment. Consequently an important issue is the future determinants of current behavior. This issue is studied, for the case of stock prices, by a sizeable strand of literature in Finance, launched by the work of Campbell and Shiller (1988). A key concern in this literature has been the question of what is the relative importance of dividend growth and of future returns for stock price volatility. I make use of the methodologies developed in this literature, surveyed by Cochrane (2005, 2011), Lettau and Ludvigson (2009), and Koijen and Van Nieuwerburgh (2010), to determine the relative importance of the future determinants of current hiring and current investment.

\section{The Model}

I delineate a partial equilibrium model which serves as the basis for estimation. ${ }^{9}$ There are identical workers and identical firms, who live forever and have rational expectations. All variables are expressed in terms of the output price level. Firms make gross investment $(i)$ and gross hiring $(h)$ decisions ${ }^{10}$. Once a new worker is hired, the firm pays her a per-period wage $w$. Firms use physical capital $(k)$ and labor $(n)$ as inputs in order to

\footnotetext{
${ }^{9}$ This formulation is consistent with the afore-cited analysis in Merz and Yashiv (2007). The parts concerned with the labor market are consistent with the prototypical search and matching model within a stochastic framework. See Pissarides (2000) and Yashiv (2007).

${ }^{10}$ In the standard search and matching model, gross hires are labeled new job-matches.
} 
produce output goods $y$ according to a constant-returns-to-scale production function $f$ with productivity shock $z$ :

$$
y_{t}=f\left(z_{t}, n_{t}, k_{t}\right),
$$

Gross hiring and gross investment are subject to frictions and hence are costly activities. Frictions may pertain to many dimensions: search processes, organizational structure, technological innovation, production disruptions, financial frictions, implementation and installations lags, etc. Hiring costs may include search costs for worker attributes (such as talent), costs for advertising, screening and testing, matching frictions, training costs and more. Investment involves implementation costs, financial premia on certain projects, capital installation costs, learning the use of new equipment, etc. Both activities may involve, in addition to production disruption, also the implementation of new organizational structures within the firm and new production practices. All of these costs reduce the firm's profits. I represent these costs by a function $g\left[i_{t}, k_{t}, h_{t}, n_{t}\right]$ which is convex in the firm's decision variables and exhibits constant returns-to-scale, allowing hiring costs and investment costs to interact. I specify and justify the functional form of $g$ and discuss its properties below.

In every period $t$, the capital stock depreciates at the rate $\delta_{t}$ and is augmented by new investment $i_{t}$. The capital stock's law of motion equals:

$$
k_{t+1}=\left(1-\delta_{t}\right) k_{t}+i_{t}, \quad 0 \leq \delta_{t} \leq 1
$$

Similarly, workers separate at the rate $\psi_{t}$. It is augmented by new hires $h_{t}$ :

$$
n_{t+1}=\left(1-\psi_{t}\right) n_{t}+h_{t}, \quad 0 \leq \psi_{t} \leq 1 .
$$

Note that hiring and separations are both gross flows and that the separation rate is time-varying. Equations (6) and (7) feature a time lag of one period in the activation of capital and labor.

Firms' profits before tax, $\pi$, equal the difference between revenues net of investment and hiring costs and total labor compensation, wn:

$$
\pi_{t}=\left[f\left(z_{t}, n_{t}, k_{t}\right)-g\left(i_{t}, k_{t}, h_{t}, n_{t}\right)\right]-w_{t} n_{t} .
$$

Every period, firms make after-tax cash flow payments $c f$ to the stock owners and bond holders of the firm. These cash flow payments equal profits after tax minus purchases of investment goods plus investment tax credits and depreciation allowances for new investment goods:

$$
c f_{t}=\left(1-\tau_{t}\right) \pi_{t}-\left(1-\chi_{t}-\tau_{t} D_{t}\right) \widetilde{p}_{t}^{I} i_{t}
$$

where $\tau_{t}$ is the corporate income tax rate, $\chi_{t}$ the investment tax credit, $D_{t}$ the present discounted value of capital depreciation allowances, $\tilde{p}_{t}^{I}$ the real pre-tax price of investment goods. 
The discount factor between periods $t+j-1$ and $t+j$ for $j \in\{1,2, \ldots\}$ is given by:

$$
\beta_{t+j}=\frac{1}{1+r_{t+j-1, t+j}}
$$

where $r_{t+j-1, t+j}$ denotes the time-varying discount rate between periods $t+j-1$ and $t+j$. Appendix B contains a description of how alternative values of the discount rate $r$ are computed in the empirical work.

The representative firm chooses sequences of $i_{t}$ and $h_{t}$ in order to maximize its cum dividend market value $c f_{t}+s_{t}$ :

$$
\max _{\left\{i_{t+j}, h_{t+j}\right\}} E_{t}\left\{\sum_{j=0}^{\infty}\left(\prod_{i=0}^{j} \beta_{t+i}\right) c f_{t+j}\right\}
$$

subject to the definition of $c f_{t+j}$ in equation (9) and the constraints (6) and (7). The firm takes the paths of the variables $w, p^{I}, \delta, \psi, \tau$ and $\beta$ as given. The Lagrange multipliers associated with these two constraints are $Q_{t+j}^{K}$ and $Q_{t+j}^{N}$, respectively. These Lagrange multipliers can be interpreted as marginal $Q$ for physical capital, and marginal $Q$ for employment, respectively.

The first-order conditions for dynamic optimality are the same for any two consecutive periods $t+j$ and $t+j+1, j \in\{0,1,2, \ldots\}$. For the sake of notational simplicity, I drop the subscript $j$ from the respective equations to follow:

$$
\begin{aligned}
Q_{t}^{K} & =E_{t}\left\{\beta_{t+1}\left[\left(1-\tau_{t+1}\right)\left(f_{k_{t+1}}-g_{k_{t+1}}\right)+\left(1-\delta_{t+1}\right) Q_{t+1}^{K}\right]\right\} \\
Q_{t}^{K} & =\left(1-\tau_{t}\right)\left(g_{i_{t}}+p_{t}^{I}\right) \\
Q_{t}^{N} & \left.=E_{t}\left\{\beta_{t+1}\left[\left(1-\tau_{t+1}\right)\left(f_{n_{t+1}}-g_{n_{t+1}}-w_{t+1}\right)+\left(1-\psi_{t+1}\right) Q_{t+1}^{N}\right] 1\right] 3\right) \\
Q_{t}^{N} & =\left(1-\tau_{t}\right) g_{h_{t}}
\end{aligned}
$$

where I use the real after-tax price of investment goods, given by:

$$
p_{t+j}^{I}=\frac{1-\chi_{t+j}-\tau_{t+j} D_{t+j}}{1-\tau_{t+j}} \widetilde{p}_{t+j}^{I} .
$$

Dynamic optimality requires the following two transversality conditions to be fulfilled

$$
\begin{aligned}
& \lim _{T \rightarrow \infty} E_{T}\left(\beta_{T} Q_{T}^{K} k_{T+1}\right)=0 \\
& \lim _{T \rightarrow \infty} E_{T}\left(\beta_{T} Q_{T}^{N} n_{T+1}\right)=0 .
\end{aligned}
$$

I can summarize the firm's first-order necessary conditions from equations (11)-(14) by the following two expressions:

$$
\begin{aligned}
\left(1-\tau_{t}\right)\left(g_{i_{t}}+p_{t}^{I}\right) & \left.=E_{t}\left\{\beta_{t+1}\left(1-\tau_{t+1}\right)\left[\begin{array}{c}
f_{k_{t+1}}-g_{k_{t+1}} \\
+\left(1-\delta_{t+1}\right)\left(g_{i_{t+1}}+p_{t+1}^{I}\right)
\end{array}\right]\right\}\right) \\
\left(1-\tau_{t}\right) g_{h_{t}} & =E_{t}\left\{\beta_{t+1}\left(1-\tau_{t+1}\right)\left[\begin{array}{c}
f_{n_{t+1}}-g_{n_{t+1}}-w_{t+1} \\
+\left(1-\psi_{t+1}\right) g_{h_{t+1}}
\end{array}\right]\right\} .(18)
\end{aligned}
$$


Solving equation (11) forward and using the law of iterated expectations expresses $Q_{t}^{K}$ as the expected present value of future marginal products of physical capital net of marginal investment costs:

$Q_{t}^{K}=E_{t}\left\{\sum_{j=0}^{\infty}\left(\prod_{i=0}^{j} \beta_{t+1+i}\right)\left(\prod_{i=0}^{j}\left(1-\delta_{t+1+i}\right)\right)\left(1-\tau_{t+1+j}\right)\left(f_{k_{t+1+j}}-g_{k_{t+1+j}}\right)\right\}$.

It is straightforward to show that in the special case of time-invariant discount factors, no costs, no taxes, and a perfectly competitive market for capital, $Q_{t}^{K}$ equals one. Similarly, solving equation (13) forward and using the law of iterated expectations expresses $Q_{t}^{N}$ as the expected present value of the future stream of surpluses arising to the firm from an additional hire of a new worker:

$Q_{t}^{N}=E_{t}\left\{\sum_{j=0}^{\infty}\left(\prod_{i=0}^{j} \beta_{t+1+i}\right)\left(\prod_{i=0}^{j}\left(1-\psi_{t+1+i}\right)\right)\left(1-\tau_{t+1+j}\right)\left(f_{n_{t+1+j}}-g_{n_{t+1+j}}-w_{t+1+j}\right)\right\}$.

In the special case of a perfectly competitive labor market and no hiring costs, $Q_{t}^{N}$ equals zero.

\section{Estimation}

I estimate alternative versions of the model. The alternatives pertain to the degree of convexity of the costs function, the possibility that hiring costs may depend on labor market conditions, the formulation of the discount rate, the examination of standard specifications, and the set of instruments used. I estimate equations (17) and (18), using structural estimation. In what follows I present the parameterization of this function (as well as of the production function), the econometric methodology, the data and the results.

\subsection{Methodology}

\subsubsection{Parameterization}

To estimate the model I need to parameterize the relevant functions. For the production function I use a standard Cobb-Douglas formulation:

$$
f\left(z_{t}, n_{t}, k_{t}\right)=e^{z_{t}} n_{t}{ }^{\alpha} k_{t}^{1-\alpha}, 0<\alpha<1 .
$$

The costs function g, capturing the different frictions in the hiring and investment processes, is at the focus of the estimation work and merits discussion. It is meant to capture all the frictions involved, and not, say, just 
adjustment costs or vacancy costs. One should keep in mind that it is formulated as the costs function of the representative firm within a macroeconomic model, and not one of a single firm in a heterogenous firms micro set-up.

Functional Form. The parametric form I use is the following, generalized convex function.

$$
g(\cdot)=\left[\begin{array}{c}
\frac{e_{1}}{\eta_{1}}\left(\frac{i_{t}}{k_{t}}\right)^{\eta_{1}} \\
+\left[\frac{e_{20}+e_{21} \frac{v_{t}}{u_{t}+o_{t}}}{\eta_{2}}\right]\left(\frac{h_{t}}{n_{t}}\right)^{\eta_{2}} \\
+\left[\frac{e_{30}+e_{31} \frac{v_{t}}{u_{t}+o_{t}}}{\eta_{3}}\right]\left(\frac{i_{t}}{k_{t}} \frac{h_{t}}{n_{t}}\right)^{\eta_{3}}
\end{array}\right] f\left(z_{t}, n_{t}, k_{t}\right) .
$$

This function is linearly homogenous in its arguments $i, k, h, n, v, o$, and $u$. The parameters $e_{l}, l=1,20,21,30,31$ express scale, and the parameters $\eta_{1}, \eta_{2}, \eta_{3}$ express the elasticity of costs with respect to the different arguments. I rationalize the use of this form in what follows.

Arguments of the function. This specification captures the idea that frictions or costs increase with the extent of the activity in question, hiring or investment. The latter needs to be modelled relative to the size of the firm. The intuition is that hiring 10 workers, for example, means different levels of activity for firms with 100 workers or firms with 10,000 workers. Hence firm size, as measured by its physical capital stock or its level of employment, is taken into account and the costs function is increasing in the investment and hiring rates, $\frac{i}{k}$ and $\frac{h}{n}$. The function used postulates that costs are proportional to output, i.e., the results can be stated in terms of lost output.

More specifically, the terms in the function presented above may be justified as follows (drawing on Garibaldi and Moen (2009)): suppose each worker $i$ makes a recruiting and training effort $h_{i}$; as this is to be modelled as a convex function, it is optimal to spread out the efforts equally across workers so $h_{i}=\frac{h}{n}$; formulating the costs as a function of these efforts and putting them in terms of output per worker I get $c\left(\frac{h}{n}\right) \frac{f}{n}$; as $n$ workers do it then the aggregate cost function is given by $c\left(\frac{h}{n}\right) f$.

Convexity. I use a convex function, allowing for free estimation of the degree of convexity. The use of such a function may be questioned at the micro-level, as non-convexities were found to be significant at that level (plant, establishment, or firm). But a number of papers have given empirical support to the use of a convex function in the aggregate, showing that a convex formulation is appropriate at the macroeconomic level. The following four papers are prominent, recent examples of this line of literature. Cooper and Haltiwanger (2006) use an indirect inference procedure to estimate the structural parameters of a rich specification of capital adjustment costs. While finding that non-convexities matter at the plant-level, they note that "...the aggregate moments...seem to be much closer to the prediction of a 
quadratic cost of adjustment model" (page 628). They state that "a model with only convex adjustment costs fits the aggregate data created by our estimated model reasonably well ...we find that the non-convexities are less important at the aggregate relative to the plant level" (page 613). Kahn and Thomas (2008, see in particular their discussion on pages 417-421) study a dynamic, stochastic, general equilibrium model with nonconvex capital adjustment costs. One key idea which emerges from their analysis is that there are smoothing effects that result from equilibrium price changes. They find that "...movements in relative prices ...eliminate the implications of plantlevel nonconvexities for aggregate dynamics (page 429)." Bloom (2009), who stresses the role of non-convexities at the firm level, cites ${ }^{11}$ the Kahn and Thomas (2008) results as not inconsistent with his and notes (page 665) that "Interestingly, industry and aggregate data are much more autocorrelated and less skewed due to extensive aggregation, suggesting quadratic adjustments costs could be a reasonable approximation at this level." Favilukis and Lin (2011) use data on asset prices as additional restrictions when examining firm investment behavior and find that "...within such a model, non-convex frictions are unnecessary to match important features of aggregate investment...a model with convex costs alone does nearly as good of a job at matching firm level micro data as our preferred model with both convex and non-convex costs" (page 26).

Main features. Noting that hiring costs include matching frictions, the terms $e_{21} \frac{v_{t}}{u_{t}+o_{t}}$ and $e_{31} \frac{v_{t}}{u_{t}+o_{t}}$ allow for the scale of costs to depend on labor market tightness $\frac{v_{t}}{u_{t}+o_{t}}$. This caters for the possibility that hiring costs - by themselves and by their interaction with investment costs - depend on the state of the labor market captured by market tightness for any given hiring rate $\frac{h}{n}$. The sign of $e_{21}$ and of $e_{31}$ may be positive or negative, as there may be different effects of these aggregate conditions on the firm hiring process. In the empirical work below, these are unconstrained parameters to be estimated.

The term $\left(\frac{i_{t}}{k_{t}} \frac{h_{t}}{n_{t}}\right)^{\eta_{3}}$ expresses the interaction of investment and hiring costs. This term, usually absent in many studies, has important implications for the complementarity of investment and hiring. It, too, is estimated without constraints.

Relation to Known Cases. The function encompasses widely-used cases as special cases. For example, the quadratic case has $\eta_{1}=\eta_{2}=2$; a standard Tobin's Q model of investment has $e_{20}=e_{21}=e_{30}=e_{31}=0$ and $\eta_{1}=2$; a Pissarides-type matching model would have $e_{1}=e_{30}=e_{31}=0, \eta_{2}=1$.

Alternative specifications. In estimation, I explore a number of alternative specifications:

1) The degree of convexity of the $g$ function. I examine restricted and free estimation of the power parameters $\eta_{1}, \eta_{2}$ and $\eta_{3}$.

\footnotetext{
${ }^{11}$ See his footnote 36 on page 653 .
} 
2) Scale as a function of market conditions. I examine the above as well as the case where labor market conditions do not matter, namely $e_{21}=e_{31}=0$.

3) Standard specifications. I set $e_{20}=e_{21}=e_{30}=e_{31}=0$ and look at investment costs only and then I set $e_{1}=e_{30}=e_{31}=0$ and look at hiring costs only. I also examine the case of both investment and hiring costs but no interaction $e_{30}=e_{31}=0$.

4) Instrument sets. I use alternative instrument sets in terms of variables and number of lags.

Estimation of the parameters in these functions allows for the quantification of the derivatives $g_{i_{t}}$ and $g_{h_{t}}$ that appear in the firms' optimality equations (17) and (18).

\subsubsection{Structural Estimation}

I structurally estimate the firms' first-order conditions (17) and (18), using Hansen's (1982) generalized method of moments (GMM). The moment conditions estimated are those obtained under rational expectations. That is, the firms' expectational errors are orthogonal to any variable in their information set at the time of the investment and hiring decisions. The moment conditions are derived by replacing expected values with actual values plus expectational errors $j$ and specifying that the errors are orthogonal to the instruments $Z$, i.e., $E\left(j_{t} \otimes Z_{t}\right)=0$. I formulate the equations in stationary terms by dividing (17) by $\frac{f_{t}}{k_{t}}$ and (18) by $\frac{f_{t}}{n_{t}}$.

The estimating equations errors $j_{t}$ are thus given by:

$$
\begin{aligned}
& j_{t}^{1}=\frac{\left(1-\tau_{t}\right)\left(g_{i_{t}}+p_{t}^{I}\right)}{\frac{f_{t}}{k_{t}}}-\left\{\frac{\frac{f_{t+1}}{k_{t+1}}}{\frac{f_{t}}{k_{t}}} \beta_{t+1}\left(1-\tau_{t+1}\right) \frac{\left[f_{k_{t+1}}-g_{k_{t+1}}+\left(1-\delta_{t+1}\right)\left(g_{i_{t+1}}+p_{t+1}^{I}\right)(2\}\right)}{\frac{f_{t+1}}{k_{t+1}}}\right. \\
& j_{t}^{2}=\frac{\left(1-\tau_{t}\right) g_{h_{t}}}{\frac{f_{t}}{n_{t}}}-\left\{\frac{\frac{f_{t+1}}{n_{t+1}}}{\frac{f_{t}}{n_{t}}} \beta_{t+1}\left(1-\tau_{t+1}\right) \frac{\left[f_{n_{t+1}}-g_{n_{t+1}}-w_{t+1}+\left(1-\psi_{t+1}\right) g_{h_{t+1}}\right]}{\frac{f_{t+1}}{n_{t+1}}}\right\}
\end{aligned}
$$

Appendix A spells out the first derivatives included in these equations.

I compute the J-statistic test of the overidentifying restrictions proposed by Hansen (1982). I also check whether the estimated $g$ function fulfills the convexity requirement.

\subsection{The Data}

The data are quarterly, pertain to the private sector of the U.S. economy, and cover the period 1976-2007. ${ }^{12}$ They include NIPA data on GDP and its deflator, capital, investment, the price of investment goods and depreciation,

\footnotetext{
${ }^{12}$ The start date of 1976 is due to the lack of availability of monthly CPS data from which the gross hiring flow series is derived.
} 
BLS CPS data on employment and on worker flows, and Fed data on the constituents of the discount factor and on tax and depreciation allowances (Fed computations). Appendix B elaborates on the sources and on data construction. These data have the following features:

(i) The data pertain to the U.S. private sector, thus not confounding the analysis with government hiring and investment.

(ii) Both hiring $h$ and investment $i$ refer to gross flows. Likewise, separation of workers $\psi$ and depreciation for capital $\delta$ are gross flows.

(iii) The estimating equations take into account taxes and depreciation allowances.

Points (ii) and (iii) require a substantial amount of computation, which is elaborated in Appendix B.

Table 3 presents key sample statistics.

Table 3

\subsection{Results}

Appendix $\mathrm{C}$ reports the results for the afore-cited alternative specifications and discusses them. Table 4a below presents only the preferred estimates of the parameters. It uses $\eta_{1}=\eta_{2}=2, \eta_{3}=1$ and $\alpha=0.68$ throughout, i.e. quadratic costs, linear interaction and a standard value for the labor share in production. The table reports the estimates and their standard errors, Hansen's (1982) J-statistic and its p-value. Note that

The first row of Table $4 \mathrm{a}$ presents estimates of a standard quadratic investment costs function with no role for hiring. The second row does the same for hiring with no investment. The third row allows for both but without any interaction between them. The fourth row is the same as the third but allows hiring costs to depend on labor market tightness. The fifth row allows for interaction of costs and the sixth row allows for both interaction of costs and dependence on labor market tightness.

\section{Table 4a}

All specifications yield precise estimates and the J-statistics do not reject the model. However, rows 1, 3 and 4 have low p-values. Row 1 with the standard quadratic specification has precise estimates but these imply very high costs; the $e_{1}$ point estimate is big, almost four times as high as the estimate of row 6 . This has been the usual result in the literature, which was highly criticized. Row 2 provides for a reasonable estimate (of $e_{20}$ ) but does not allow for investment by construction. Row 3, which allows for both, still implies very high investment costs (high $e_{1}$ ). Row 4, which does not allow for interaction either, adds the dependence of hiring on labor market conditions and produces lower investment costs, though still higher than subsequent specifications. Rows 5 and 6 allow for investment and hiring 
costs to interact. This interaction is negatively signed (see the estimate of $\left.e_{30}\right)$ and it is the ingredient which allows the model to best fit the data. Row 6 also allows for hiring costs (and their interaction with investment) to depend on labor market conditions. This dependence $\left(e_{21}\right.$ and $\left.e_{31}\right)$ turns out significant and leads to further reduction in the estimate of $e_{1}$.

The implications thus far are as follows, taking into account the alternative specifications discussed in Appendix C: quadratic costs and linear interaction of costs generate a good fit of the data; the interaction is significant and is negatively signed, implying complementarity between investment and hiring (to be discussed below); there is a significant role for labor market conditions in hiring costs, whereby the latter are lower in "good times"; the investment part is problematic if hiring is left out or if hiring is introduced without interaction or without dependence on labor market conditions. By 'problematic' I mean that one needs high investment costs (high $e_{1}$ ) to fit the data. In what follows I shall refer to the results of rows 5 and 6 as the preferred specifications.

In order to further explore the implications of these estimates and characterize the joint behavior of investment and hiring, I use them in several ways. I start by looking at the magnitude of costs, comparing them to the findings in the literature (Section 6). I then look at the right hand side of the optimality equations and use the estimates to approximate and decompose the present values of hiring and investment which drive these decisions (Section 7). The following section (8) explores the implications of the results for the co-movement and business cycle behavior of investment and hiring and their determinants.

\section{Gauging the Estimates: the Degree of Frictions}

The results of Table 4a merit inspection for plausibility and the derivation of the frictions they imply. This is done by constructing the time series for total and marginal costs implied by the point estimates of the parameters of the $g$ function and relating them to what is known on these issues.

\subsection{The Estimated Frictions}

The estimated costs are interesting and important by themselves, as many models rely on their existence. Their key moments are presented in Table $4 \mathrm{~b}$.

\section{Table $4 b$}

Essentially total costs are about $2.5 \%$ of GDP on average, with a standard deviation of $0.3 \%$. Marginal investment costs add about $6 \%$ on average to the price $p_{t}^{I}$ of a unit of capital (see below). Marginal hiring costs are 
on average the equivalent of 5 weeks of wages. To gain a better grasp of the implications of these moments, the following comparisons place them in context.

\subsection{Comparisons to the Literature}

How do these compare to the literature?

Total costs as a fraction of GDP (i.e. $\frac{g}{f}$ ) are around $2.5 \%$ of output according to the preferred specifications (rows 5 and 6 of Table 4a), a reasonable estimate, as will be discussed below.

Marginal costs of hiring (i.e. $g_{h}$ ) in terms of average output per worker $\left(\frac{f}{n}\right)$ have a sample mean of 0.26 in row 5 and of 0.28 in row 6 , the preferred specifications. This is roughly equivalent to $39 \%$ (row 5 ) or $42 \%$ (row 6 ) of quarterly wages. ${ }^{13}$ In other words, firms pay the equivalent of about 5 to 5.5 weeks of wages to hire the marginal worker.

How does one evaluate this estimate? There is little empirical evidence on these costs in the literature. In what follows I cite some estimates on average hiring costs, which typically relate only to vacancy costs. Mortensen and Nagypal (2006, page 30) note that "Although there is a consensus that hiring costs are important, there is no authoritative estimate of their magnitude. Still, it is reasonable to assume that in order to recoup hiring costs, the firm needs to employ a worker for at least two to three quarters. When wages are equal to their median level in the standard model $(\mathrm{w}=0.983)$, hiring costs of this magnitude correspond to less than a week of wages." The widely-cited Shimer (2005) paper calibrates these costs at 0.213 in terms similar to $g_{h}$ here, using a linear cost function, which is equivalent to 1.4 weeks of wages. Hagedorn and Manovskii (2008) decompose this cost into two components: (i) the capital flow cost of posting a vacancy; they compute it to be - in steady state -47.4 percent of the average weekly labor productivity; (ii) the labor cost of hiring one worker, which, relying on micro-evidence, they compute to be 3 percent to 4.5 percent of quarterly wages of a new hire. The first component would correspond to a figure of 0.037 here; the second component would correspond to a range of 0.02 to 0.03 in the terms used here; together this implies 0.057 to 0.067 in current terms or around 1.1 to 1.3 weeks of wages. Note that the results here refer not only to vacancy costs and pertain to the marginal hire with convex costs. Hence the current results are consistent with the cited estimates of average vacancy costs.

Older, micro evidence relates mostly to labor adjustment costs, which is a narrower concept than the one discussed here. These latter costs may exclude vacancy costs or matching costs, and typically they pertain to costs of net employment changes $\left(n_{t}-n_{t-1}\right)$, as distinct from gross hiring $\left(h_{t}\right)$. As

\footnotetext{
${ }^{13}$ Wages are $66 \%$ of output per worker on average, see Table 3.
} 
noted above, net and gross flows are hugely different, in terms of all moments of their distributions. The literature suggests a very wide range of estimates (see Hamermesh (1993, pp. 207-209)) and hence there is no solid benchmark in this type of studies against which to compare the current estimates.

The marginal costs of investment (i.e. $g_{i}$ ) in terms of average output per unit of capital $\left(\frac{f}{k}\right)$ have a sample mean of 0.61 in row 5 and of 0.72 in row 6 of Table 4b. ${ }^{14}$ To give another, more intuitive, perspective on these numbers, consider how much one needs to add to the price of one unit of the investment good $p^{I}$ in marginal costs: row 5 implies $5.7 \%$ on average, row 6 implies $6.7 \%$ on average. By contrast, the estimate of row 1 with only quadratic investment costs has a sample mean of 3.54 in terms of average output per unit of capital $\left(\frac{f}{k}\right)$ or $33 \%$ to be added to the price of the investment good, an implausible result.

How reasonable are these estimates? The most natural place to look for comparisons is the Q-literature. Table 5 presents nine estimates of the investment equation from this literature. The equation links the investmentto-capital ratio to a measure of Tobin's Q. Note that these studies differ from each other and from the current study on many dimensions: the data sample used, the functional form assumed for marginal costs, additional variables included in the cost function, treatment of tax issues, and reduced form vs. structural estimation. Estimates of the curvature of the marginal cost function may be conditional on additional variables included in the analysis and reduced form estimates may be consistent with several alternative underlying structural models. The studies often came in response to previous estimates, each trying to introduce changes so as to improve on the preceding ones; some of these changes were substantial. Hence, Table 5 cannot give more than a rough idea as to the "neighborhood" of costs estimates.

\section{Table 5}

The table shows huge variation across studies: it ranges from marginal costs as low as 0.04 to as high as 60 (in terms of $\frac{f}{k}$ ). It should be noted that the differences in marginal cost estimates are usually due to differences in the parameter estimates, and not just due to the diversity in the rate of investment used. One can divide the results into three sets:

(i) High costs, as in studies 1 and 2. Marginal costs range between 3 to 60 in terms of average output per unit of capital. The implied total costs range between $15 \%$ to $100 \%$ of output. This set characterizes the earlier studies.

(ii) Moderate costs, as in studies 3, 5 and 6b. Marginal costs are around 1 in terms of average output per unit of capital. Total costs range between $0.5 \%$ to $6 \%$ of output.

\footnotetext{
${ }^{14}$ The units of measurement - in terms of output per unit of capital $\frac{f}{k}$ - were chosen so as to facilitate comparison with existing studies, as discussed below.
} 
(iii) Low costs, as in the rest of the studies, namely 4, 6a, 7, 8, and 9 . Marginal costs are 0.04 to 0.50 of average output per unit of capital. Total costs range between $0.1 \%$ to $0.2 \%$ of output. The studies finding these latter magnitudes are micro studies, using cross-sectional or panel data.

Coming back to the initial question of comparing these estimates to the current findings, two conclusions emerge:

(i) The specification that I run that is closest to the one used in most studies of Table 5 is the one reported in row 1 of Table $4 \mathrm{~b}$. This is the specification positing a quadratic function and ignoring labor. The implied total costs are $4.4 \%$ of output (as in studies of the moderate costs set) and the implied marginal costs are 3.5 of average output per unit of capital (as in the high costs set). As indicated above, this is $33 \%$ of the price of a unit of investment good $p^{I}$. These implausible results are a major reason to reject these particular estimates here.

(ii) The preferred specifications - the GMM results of the full model, rows 5 and 6 of Table $4 \mathrm{~b}$ - cannot be directly compared to the results of Table 5 , as they take into account hiring costs through the interaction between hiring and investment costs and have a convex specification. In formal terms the marginal investment costs are specified by $\frac{g_{i}}{\frac{f}{k}}=\left[e_{1}\left(\frac{i}{k}\right)^{\eta_{1}-1}+\left(e_{30}+e_{31} \frac{v}{u+o}\right)\left(\frac{h}{n}\right)^{\eta_{3}}\left(\frac{i}{k}\right)^{\eta_{3}-1}\right]$ while most specifications of Table 5 posit $g_{i}=e_{1} \frac{i}{k}$. In particular, the expression in the current paper depends on $\frac{h}{n}$ in a substantial way. Nevertheless, looking at marginal costs as a fraction of output per unit of capital $\left(\frac{g_{i}}{\frac{f}{k}}\right)$, estimated at a mean of 0.61 or 0.72 , the findings of Table $4 \mathrm{~b}$ correspond to the third set, i.e., to low costs. Note that the estimation here uses aggregate time series, while the cited papers of the third set use microeconomic cross-sectional or panel data.

Overall, then, the frictions implied by the estimates are not high and are very reasonable in comparison to what is known from the literature.

\subsection{A Graphical Presentation}

Figure 2 presents plots of the estimated marginal costs functions. The plot describes functions derived from the estimates of Table $4 \mathrm{a}$.

\section{Figure 2}

Panel a shows that allowing for hiring costs has a big effect on the marginal investment costs function, moving it down substantially (compare the black line with the red and blue lines). Allowing for labor market conditions to affect the interaction of hiring costs with investment costs has a small effect, moving this function back up somewhat (compare the red and blue lines). Panel b shows similar changes for the marginal hiring cost function, 
albeit with different magnitudes. Hence, the figure clearly shows the importance of the interaction of investment and hiring costs and the (smaller) impact of labor market conditions.

\section{The Value of Investment and Hiring}

I have derived - through structural estimation - the costs function $(g)$ which defines the present value of hiring $\left(Q^{N}\right)$ and of investment $\left(Q^{K}\right)$. How are these values related to their expected future determinants, given that both hiring and investment are forward-looking variables? In other words, what in the future drives hiring and investment today? In this section, I follow the empirical methodology of the asset pricing literature in Finance and examine the present value relationships governing hiring and investment. This involves the study of the determinants of hiring and investment, using forecasting regressions, VARs and approximated relations. The analysis is based on the framework proposed by Campbell and Shiller (1988) and its more recent elaboration by Cochrane $(2005,2011)$, whose notation I follow. This model is often referred to as the dynamic, dividend-growth model. ${ }^{15}$ Note that I do not consider stock prices here; I simply apply the empirical framework developed in the cited Finance literature to the current context. As mentioned above, the connections between the current framework and stock prices were explored in Merz and Yashiv (2007). ${ }^{16}$ The results in the Finance literature do, however, provide a natural benchmark against which to compare the current results.

\subsection{An Asset Pricing Model}

The model begins from the following two-period representation for the stock price $(P)$ and dividends $(D)$ :

$$
\begin{aligned}
P_{t} & =E_{t}\left(R_{t+1}^{-1}\left[D_{t+1}+P_{t+1}\right]\right) \\
\frac{P_{t}}{D_{t}} & =E_{t}\left(R_{t+1}^{-1}\left[\frac{D_{t+1}}{D_{t}}+\frac{D_{t+1}}{D_{t}} \frac{P_{t+1}}{D_{t+1}}\right]\right)
\end{aligned}
$$

where $R$ is the gross return. Iterated forward this yields:

$$
\frac{P_{t}}{D_{t}}=E_{t}\left(\sum_{j=0}^{\infty}\left(\prod_{k=1}^{j+1} R_{t+k}^{-1} \frac{D_{t+k}}{D_{t+k-1}}\right)\right)
$$

\footnotetext{
${ }^{15}$ Lettau and Ludvigson (2009), Koijen and Van Nieuwerburgh (2010) and Cochrane (2011) provide surveys of these empirical studies and a discussion of their implications for asset pricing.

${ }^{16}$ See also Jermann (1998).
} 
These relationships hold true also ex-post if one defines returns as:

$$
R_{t}=\frac{D_{t+1}+P_{t+1}}{P_{t}}
$$

Using logs, this asset pricing relationship can be approximated as:

$$
p_{t}-d_{t}=k+E_{t}\left(d_{t+1}-d_{t}-r_{t+1}+\rho\left(p_{t+1}-d_{t+1}\right)\right)
$$

where:

$$
\begin{aligned}
p_{t} & \equiv \ln P_{t} \\
d_{t} & =\ln D_{t} \\
r_{t} & =\ln R_{t} \\
k & =\ln \left(1+\frac{P}{D}\right)-\rho(p-d) \\
\rho & =\frac{\frac{P}{D}}{1+\frac{P}{D}}
\end{aligned}
$$

and where $P, D$ are steady state or long-term average values.

Equation (28) is an ex-ante formulation using conditional expectations. The following ex-post equation holds true as well, when using (27):

$$
p_{t}-d_{t}=k+\left(d_{t+1}-d_{t}-r_{t+1}+\rho\left(p_{t+1}-d_{t+1}\right)\right)
$$

Based on (29), the following ex-post relations in levels and in variance hold true in approximation:

$$
\begin{array}{r}
p_{t}-d_{t} \simeq \sum_{j=1}^{\infty} \rho^{j-1} k+\left(\sum_{j=0}^{\infty} \rho^{j}\left(d_{t+j+1}-d_{t+j}-r_{t+j+1}\right)\right) \\
\operatorname{var}\left(p_{t}-d_{t}\right) \simeq \operatorname{cov}\left[p_{t}-d_{t}, \sum_{j=0}^{\infty} \rho^{j-1}\left(d_{t+j+1}-d_{t+j}\right)\right] \\
-\operatorname{cov}\left[p_{t}-d_{t}, \sum_{j=0}^{\infty} \rho^{j-1} r_{t+j+1}\right]
\end{array}
$$

The current price dividend ratio $\left.\left(p_{t}-d_{t}\right)\right)$ is related to future dividend growth $\left(d_{t+j+1}-d_{t+j}\right)$ and to future returns $\left(r_{t+j+1}\right)$, with the relevant discounting (using $\rho^{j}$ ). The price-dividend ratio will be higher when future dividend growth is higher and/or when future returns are lower. 


\subsection{Empirical Methodology}

These relationships have been examined in the Finance literature in a number of ways.

Forecasting Regressions. One way is to estimate forecasting regressions of the type:

$$
\begin{aligned}
\left(p_{t+1}-d_{t+1}\right) & =a+\phi\left(p_{t}-d_{t}\right)+e_{p, t} \\
d_{t+1}-d_{t} & =c+b_{d}\left(p_{t}-d_{t}\right)+e_{d, t} \\
r_{t+1} & =d+b_{r}\left(p_{t}-d_{t}\right)+e_{r, t}
\end{aligned}
$$

The log price dividend ratio $\left(p_{t}-d_{t}\right)$ is expected to forecast future dividend growth $\left(d_{t+1}-d_{t}\right)$ and/or future returns $\left(r_{t+1}\right)$. These equations are examined as separate regressions or within a system. The last two regressions have been estimated also using a longer horizons, so on the LHS may appear longer horizon dividend growth $\left(d_{t+H}-d_{t}\right)$ or compounded returns $\left(r_{s, t+H}=r_{s, t+1}+r_{t+1, t+2}+\ldots+r_{t+H-1, t+H}\right)$, where $H$ is the forecast horizon. Using equation (29), the coefficients in this system should obey the restriction:

$$
b_{d}-b_{r}=1-\rho \phi
$$

VAR Estimation. A second, more general formulation, encompassing (32) as a special case, is to estimate a restricted VAR on the de-meaned variables:

$$
\left(\begin{array}{c}
p_{t+1}-d_{t+1} \\
d_{t+1}-d_{t} \\
r_{t+1}
\end{array}\right)=B\left(\begin{array}{c}
p_{t}-d_{t} \\
d_{t}-d_{t-1} \\
r_{t}
\end{array}\right)+\left(\begin{array}{c}
\varepsilon_{1_{t}} \\
\varepsilon_{2_{t}} \\
\varepsilon_{3_{t}}
\end{array}\right)
$$

Defining:

$$
\begin{aligned}
z_{t} & =\left(\begin{array}{c}
p_{t}-d_{t} \\
d_{t}-d_{t-1} \\
r_{t}
\end{array}\right), \text { with the variables de-meaned } \\
e_{1} & =(1,0,0) \\
e_{2} & =(0,1,0) \\
e_{3} & =(0,0,1) \\
\varepsilon_{t} & =\left(\begin{array}{c}
\varepsilon_{1_{t}} \\
\varepsilon_{2_{t}} \\
\varepsilon_{3_{t}}
\end{array}\right)
\end{aligned}
$$

This VAR can be written as:

$$
z_{t+1}=B z_{t}+\underline{\varepsilon}
$$

Equations (29) and (30) can be written in the same terms as: 


$$
\begin{aligned}
e_{1} z_{t} & =k+e_{2} z_{t+1}-e_{3} z_{t+1}+\rho e_{1} z_{t+1} \\
& =k+e_{2} z_{t+1}-e_{3} z_{t+1}+\rho\left(k+e_{2} z_{t+2}-e_{3} z_{t+2}+\rho e_{1} z_{t+2}\right) \\
& =\sum_{j=1}^{\infty} \rho^{j-1} k+\sum_{j=0}^{\infty} \rho^{j}\left(e_{2}-e_{3}\right) B^{j+1} z_{t}
\end{aligned}
$$

Hence the restrictions for this VAR are (allowing for de-meaning, hence dropping the first term on the RHS):

$$
e_{1} z_{t}=\sum_{j=0}^{\infty} \rho^{j}\left(e_{2}-e_{3}\right) B^{j+1} z_{t}
$$

which gives:

$$
e_{1}(I-\rho B)-\left(e_{2}-e_{3}\right) B=0
$$

Note that restriction (33) is a special case of the last set of restrictions (38).

Variance Decomposition. A third way used by this empirical literature is to truncate the RHS of the variance decomposition (31) at date $T$ and compute its components.

Links. To connect the first and third ways, note the following (see Cochrane (2011, pp. 2-4)). First, divide (33) by $1-\rho \phi$ to get:

$$
\frac{b_{d}}{1-\rho \phi}-\frac{b_{r}}{1-\rho \phi}=1
$$

Define:

$$
\begin{aligned}
b_{d}^{l r} & =\frac{b_{d}}{1-\rho \phi} \\
b_{r}^{l r} & =\frac{b_{r}}{1-\rho \phi}
\end{aligned}
$$

to be the long run regression coefficients of log dividend growth on the log price -dividend ratio and of $\log$ returns on the $\log$ price -dividend ratio (i.e., coefficients of the regressions of $\sum_{j=0}^{\infty} \rho^{j-1}\left(d_{t+j+1}-d_{t+j}\right)$ on $p_{t}-d_{t}$ and of $\sum_{j=0}^{\infty} \rho^{j-1} r_{t+j+1}$ on $\left.p_{t}-d_{t}\right)$.

This means:

$$
b_{d}^{l r}-b_{r}^{l r}=1
$$

From the third type of computation, divide (31) throughout by $\operatorname{var}\left(p_{t}-\right.$ $\left.d_{t}\right)$ to get: 


$$
\begin{aligned}
1 \simeq & \operatorname{cov}\left[p_{t}-d_{t}, \sum_{j=0}^{\infty} \rho^{j-1}\left(d_{t+j+1}-d_{t+j}\right)\right] \\
& -\operatorname{cov}\left[p_{t}-d_{t}, \sum_{j=0}^{\infty} \rho^{j-1} r_{t+j+1}\right]
\end{aligned}
$$

This too yields:

$$
b_{d}^{l r}-b_{r}^{l r} \simeq 1
$$

Employing the first way, one gets estimates of $b_{d}^{l r}$ and $b_{r}^{l r}$ by running regressions using the whole sample. Employing the third way, one gets estimates of $b_{d}^{l r}$ and $b_{r}^{l r}$ by computing the truncated (T periods) co-variance terms.

\subsection{Implementing the Forecasting Model for Hiring and In- vestment}

I cast the estimated model of hiring and investment into this asset pricing framework by defining $P$ and $D$ for the optimal investment equation and for the optimal hiring equation. The "price" $P$ is the value of investment or the value of hiring; this is essentially marginal Q for capital investment $\left(Q^{K}\right)$ and marginal $\mathrm{Q}$ for labor hiring $\left(Q^{N}\right)$, each divided by the relevant productivity; the "dividend" $D$ is the flow of net income from capital or from labor.

Consider the investment equation (see equation (17)):

$\frac{\left(1-\tau_{t}\right)\left(g_{i_{t}}+p_{t}^{I}\right)}{\frac{f_{t}}{k_{t}}}=\left\{\frac{\frac{f_{t+1}}{k_{t+1}}}{\frac{f_{t}}{k_{t}}} \frac{\beta_{t+1}\left(1-\tau_{t+1}\right)}{\frac{f_{t+1}}{k_{t+1}}}\left[f_{k_{t+1}}-g_{k_{t+1}}+\left(1-\delta_{t+1}\right)\left(g_{i_{t+1}}+p_{t+1}^{I}\right)\right]\right\}$

I define the following asset pricing terms:

$$
\begin{aligned}
P_{t+k}^{1} & =\frac{\left(1-\tau_{t+k}\right)\left(g_{i_{t+k}}+p_{t+k}^{I}\right)}{\frac{f_{t+k}}{k_{t+k}}} \equiv \frac{Q_{t+k}^{K}}{\frac{f_{t+k}}{k_{t+k}}} \\
D_{t+k}^{1} & \equiv \frac{\left(1-\tau_{t+k}\right) \frac{\left(f_{k_{t+k}}-g_{k_{t+k}}\right)}{\frac{f_{t+k}}{k_{t+k}}}}{\left(1-\delta_{t}\right)}
\end{aligned}
$$

Likewise for the hiring equation (see equation (18)): 


$$
\frac{\left(1-\tau_{t}\right) g_{h_{t}}}{\frac{f_{t}}{n_{t}}}=\left\{\frac{\frac{f_{t+1}}{n_{t+1}}}{\frac{f_{t}}{n_{t}}} \frac{\beta_{t+1}\left(1-\tau_{t+1}\right)}{\frac{f_{t+1}}{n_{t+1}}}\left[f_{n_{t+1}}-g_{n_{t+1}}-w_{t+1}+\left(1-\psi_{t+1}\right) g_{h_{t+1}}\right]\right\}
$$

I define:

$$
\begin{aligned}
P_{t+k}^{2} & \equiv \frac{\left(1-\tau_{t+k}\right) g_{h_{t+k}}}{\frac{f_{t+k}}{n_{t+k}}} \equiv \frac{Q_{t+k}^{N}}{\frac{f_{t+k}}{n_{t+k}}} \\
D_{t+k}^{2} & =\frac{\left(1-\tau_{t+k}\right)\left(\frac{f_{n_{t+k}}-g_{n_{t+k}}-w_{t+k}}{\frac{f_{t+k}}{n_{t+k}}}\right)}{1-\psi_{t}}
\end{aligned}
$$

These prices and "dividends" are not observed on the market, as in the Finance literature. Rather, they represent what the firm actually gets from its use of capital and labor in production. Thus, the "dividend" in the investment case is the net marginal productivity of capital; in the hiring case it is net labor profitability, i.e., the net marginal product of labor less the wage. These "dividends" do not depend on institutional or financial considerations of firms as dividends do in the Finance context. Note that a version of equation (39) was used by Cochrane $(1991,1996)$ and by Liu, Whited and Zhang (2009) for production-based asset pricing, exploring it empirically in a cross-section of firms. As noted, the results in Finance provide for a natural benchmark, as in both cases the issue is future discounted flows accruing to the firm being related to current values through the asset pricing relationship.

\subsection{Results}

Table 6 presents the different tests discussed above, separately for the two equations - investment and hiring. ${ }^{17}$

\section{Table 6}

There are a number of results which stand out:

Forecasting Regressions

(i) In the single variable forecasting regressions, most coefficients are significant. This implies that capital productivity growth, labor profitability

\footnotetext{
${ }^{17}$ When presenting the approximated variance decomposition, I report the error of the approximated variance equation (31) divided by the variance of the log price-dividend ratio, $\frac{e}{\operatorname{var}\left(p_{t}-d_{t}\right)}$, namely the difference between the LHS and the RHS divided by the LHS. Note from equation (31) that this can be positive or negative. This error comes from estimation and approximation errors and from the sample truncation.
} 
growth, and returns are forecastable or predictable by the "price-dividend" ratio.

(ii) In the case of hiring, the single variable forecasting regressions adjusted R-squared $\left(\bar{R}^{2}\right)$ increases with the forecast horizon for labor profitability growth, reaching high levels of almost 0.80 at 16 and 20 quarters. The forecasted growth is the change in log labor profitability, i.e., after-tax labor productivity less wages. For the return forecast these adjusted Rsquared decrease with the forecast horizon to around 0 . At four quarters, the $\bar{R}^{2}$ is around 0.30 . This means that labor profitability growth is highly forecastable and returns are much less so.

(iii) In the case of investment, the single variable forecasting regressions $\bar{R}^{2}$ increase with the forecast horizon for capital productivity growth and for the return forecast. At 20 quarters they reach about 0.20 for capital productivity growth and almost 0.40 for the return forecast.

Points (i)-(iii) indicate results which are markedly different from those typically obtained in the Finance literature (albeit, there, relating to stock market variables). Here there is far better forecasting power for the hiring equation, especially with respect to labor profitability growth. ${ }^{18}$ In the Finance literature, the values of the $\bar{R}^{2}$ coefficients noted above are seldom higher than 0.10 for one-period forecasts and are at most 0.30 for long horizon forecasts in terms of future returns. They are around 0 for future dividend growth. Likewise, dividend growth coefficients are typically not statistically significant in that literature. The results for the investment equation here are somewhat more similar to those obtained in this Finance literature and so is also the pattern of a rise in explanatory power with the forecast horizon.

\section{VAR Estimation}

(iv) The analysis for hiring indicates that the hiring "price-dividend" ratio is persistent ( $\phi$ and $b_{p p}$ are estimated to be above 0.9 ), that a simple restricted system produces estimates similar to the single-variable regressions, and that the complete, restricted VAR analysis indicates a stronger predictive effect for labor profitability growth $\left(b_{d p}>b_{d}\right)$ and a weaker one for returns $\left(\left|b_{r p}\right|<\left|b_{r}\right|\right)$, relative to the single-variable regressions. All estimated coefficients are significant.

(v) The analysis for investment indicates that the investment "pricedivided" ratio is extremely persistent ( $\phi$ and $b_{p p}$ are estimated to be around 0.99), a finding that is similar to many Finance studies for stock-price to dividend ratios. The simple restricted system produces estimates similar to the single-variable regressions. The complete, restricted VAR analysis indicates a stronger predictive effect for capital productivity growth $\left(b_{d p}>\right.$

\footnotetext{
${ }^{18}$ Compare, for example, the results here to those discussed by Lettau and Ludvigson (2009), Koijen and Van Nieuwerburgh (2010) and Cochrane (2011).
} 
$\left.b_{d}\right)$ and a weaker one for returns $\left(\left|b_{r p}\right|<\left|b_{r}\right|\right)$, relative to the single-variable regressions. But the $\bar{R}^{2}$ in some of the investment VAR equations is low or even negative and the estimate of $b_{d}$ is insignificant.

Points (iv) and (v) basically show that the single regressions, systems, and VARs yield similar results, but that the complete, restricted VARs assign different strength to the predictor variable.

\section{Variance Decomposition}

(vi) In the hiring case, the variance decomposition yields approximated values that have a relatively small error (see last row of panel c). There is also a close correspondence between the variance decomposition results and the estimates of long run coefficients. It indicates that hiring values co-move more with future labor profitability growth (around 60\% to $80 \%$ of the variance of "price-dividend" ratios) than with future returns (the complementary $40 \%$ to $20 \%$, in absolute value). Even a small number of periods $(T=10)$ suffices to get this result in the approximated relationship.

(vii) In the investment case, the variance decomposition yields approximated values that have a relatively small error only at long horizons (i.e., at a high value of $T$ ). It indicates that investment values co-move more with future returns (around $50 \%$ to $80 \%$ of the variance of price-dividend ratios in absolute value) than with future capital productivity growth (the complementary $50 \%$ to $20 \%$ ).

Points (vi) and (vii) imply that hiring and investment relate differentially to their future determinants, with hiring dependent on future changes in labor profitability, while investment is dependent on future returns.

\section{Overall Findings}

Taken together, the results indicate that the connection between "pricedividend" ratios with future variables is significant and seems stronger or tighter for hiring than for investment. Both are stronger or much stronger than the typical findings in the Finance literature for stock price-dividend ratios. Hiring values are linked more to future changes in labor profitability, while investment values are linked more to changes in future returns.

The findings for hiring are consistent with the cyclical behavior of labor profitability. The key element in profitability here is $\frac{f_{n_{t}-w_{t}}}{\frac{f_{t}}{n_{t}}}=\alpha-\frac{w_{t}}{\frac{f_{t}}{n_{t}}}$. Real unit labor costs (or the labor share in income), $\frac{w_{t}}{\frac{f_{t}}{n_{t}}}$, are counter-cyclical contemporaneously, displaying a correlation of -0.38 with HP-filtered log GDP, so labor profitability falls in recessions. Without forward-looking behavior, one would expect hiring to fall and thus be pro-cyclical. But the dynamic cross-correlation $\rho\left(f_{t}, \frac{w_{t+l}}{\frac{f_{t+l}}{n_{t+l}}}\right)$ turns positive within a 2 quarters lead, and remains so up to 19 quarters ahead. In other words, unit labor costs fall following recessions. In fact, the correlation with HP-filtered log GDP is 
+0.40 between 4 and 10 quarters ahead, i.e., costs go down and profitability rises going forward after a recession. ${ }^{19}$ Hence forward-looking hiring is counter-cyclical and rises in recessions.

\section{The Co-Movement and Cyclical Behavior of Hir- ing and Investment}

This section examines the implications of the estimates for the co-movement of hiring and investment and their cyclical behavior. It begins with a discussion of the significance of the finding of negative interaction (sub-section 8.1). This is followed by a discussion of the sensitivity of investment and hiring to their present values (8.2). The second moments related to comovement and cyclical analysis are presented and discussed (8.3). Finally, sub-section 8.4 offers a summing-up of the mechanism.

\subsection{Negative Interaction Engenders Simultaneity}

Across all specifications of Table 4a, the estimate of the coefficient of the interaction term, $e_{30}$, is negative. This negative point estimate implies a negative value for $g_{h i}$ and, therefore, a positive sign for $\partial h_{t} / \partial Q^{k}$ and for $\partial i_{t} / \partial Q^{n}$ (for the full derivations of these derivatives, as well as the relevant elasticities, see Appendix A.) Note that $\partial i_{t} / \partial Q^{k}$ and $\partial h_{t} / \partial Q^{n}$ are positive due to convexity. Hence, when the marginal value of investment $Q^{K}$ rises, both investment and hiring rise. A similar argument shows that they both rise when the marginal value of hiring $Q^{N}$ rises.

The signs of these elasticities and derivatives imply that for given levels of investment, total and marginal costs of investment decline as hiring increases. Similarly, for given levels of hiring, total and marginal costs of hiring decline as investment increases. This finding of complementarity between investment and hiring is to be expected as it implies that they should be simultaneous. One interpretation of this result is that simultaneous hiring and investment is less costly than sequential hiring and investment of the same magnitude. This may be due to the fact that simultaneous action by the firm is less disruptive to production than sequential action. This feature is quantified by the following 'scope' statistic:

$$
\frac{g\left(0, \frac{h}{n}\right)+g\left(\frac{i}{k}, 0\right)-g\left(\frac{i}{k}, \frac{h}{n}\right)}{g\left(\frac{i}{k}, \frac{h}{n}\right)}
$$

The statistic measures how much - in percentage terms - is simultaneous investment and hiring cheaper than non-simultaneous action. Its sample mean and standard deviation are presented in the first column of Table 7 .

\footnotetext{
${ }^{19}$ This cyclicality pattern of the labor share over time is documented and analyzed by Rios-Rull and Santaeulalia-Llopis (2010).
} 


\section{Table 7}

The scope is 0 by construction in rows $1-5$ as there is no cost interaction there. For the preferred specifications, it is on average $61 \%$ (row 5 ) or $23 \%$ (row 6) out of total costs. This means that there are substantial savings of costs when investing and hiring at the same time. Hence the preferred estimates of rows 5 and 6 in Table 4a imply that there is meaningful interrelation between hiring and investment costs. The decision by the firm on one factor is strongly dependent on the other.

\subsection{The Elasticities of Hiring and Investment w.r.t Present Values}

Table 7 further quantifies the relations between hiring and investment by presenting the mean and standard deviation of the elasticities of investment $i$ and of hiring $h$ with respect to the present values $Q^{k}$ and $Q^{n}$. The table shows that the investment is very highly elastic with respect to the present value of investing $Q^{K}$; the high elasticities of rows 4 to 6 contrast with the relatively low elasticity of row 1 . This is consistent with the finding of high costs and therefore low elasticity in row 1 relative to the other formulations. Hiring has around unitary elasticity with respect to its present value $Q^{N}$. The cross elasticities are low for investment w.r.t $Q^{N}$ (an elasticity of around 0.3-0.4) and high for hiring w.r.t $Q^{K}$ (1.7 and 3.3).

The following distinction, however, is important. The preceding subsection has shown that optimal behavior includes simultaneous hiring and investment, i.e., positive levels of both $\left(\frac{i}{k}, \frac{h}{n}>0\right)$. Thus the representative firm is hiring and investing at the same time. But it does not necessarily imply highly positive co-movement or correlation between hiring and investment. In other words, investment and hiring take place at the same time, but it is possible to have one rise while the other rises, stays the same or even declines. Suppose, for example, $Q^{K}$ rises while $Q^{N}$ declines. The rise in $Q^{K}$ will lead to higher investment and higher hiring, while the fall in $Q^{N}$ will lead to lower investment and lower hiring. The elasticity estimates of Table 7 imply that the $Q^{K}$ movements and the $Q^{N}$ movements engender different responses. Therefore it is possible that investment will rise with the rise in $Q^{K}$ while hiring falls with the fall in $Q^{N}$. This is indeed what is found in this sample, as discussed in the following sub-section.

\subsection{Co-Movement and Cyclical Analysis}

To see the afore-going relations in the data, Figure 3 shows the sample behavior of $\frac{i}{k}$ and $\frac{h}{n}$, of the estimated $Q^{K}$ (net of $p^{I}$ ) and of the estimated $Q^{N}$ using the point estimates of row 6 of Table $4 \mathrm{a}$, and the behavior of non-financial business sector GDP $f$. The series are all logged and HP or 
BP filtered. Table 8 shows the co-movement of the same series, contemporaneously and in dynamic cross-correlations.

\section{Figure 3 and Table 8}

The figure and the table indicate the following:

(i) The investment rate moves together with the estimated $Q^{K}$ (net of $p^{I}$ ), contemporaneously, with a correlation of around 0.85 , and at lags and leads up to a year.

(ii) The hiring rate moves together with the estimated $Q^{N}$, contemporaneously, with a correlation of around 0.40 , and at leads up to two years, though the relation weakens in the dynamic cross-correlations.

The results of points (i) and (ii) are consistent with the elasticities reported in Table 7 .

(iii) There is negative co-movement of $Q^{K}$ (net) and $Q^{N}$, contemporaneously with a correlation of about -0.90 , and at lags and leads of up to a year. This is consistent with a negative co-movement of the investment and hiring rates themselves, contemporaneously with a correlation of -0.10 or -0.20 (depending on the filtering) and at two year lags. Investment and hiring rates thus follow similar patterns of cross correlations as do their marginal $Q s$, albeit with lower correlations in absolute value.

(iv) Investment rates $\frac{i}{k}$, the estimated marginal investment costs $\frac{g_{i}}{f / k}$, and the estimated $Q^{K}$ (net of $p^{I}$ ) are all pro-cyclical, contemporaneously and up to 1 year lags and leads under all specifications.

(v) Hiring rates $\frac{h}{n}$, the estimated marginal hiring costs $\frac{g_{h}}{f / n}$ and the estimated $Q^{N}$ are all counter-cyclical, contemporaneously and usually up to 1 year lags and leads under all specifications.

(vi) Comparing panels IIc and IId, which differ in modelling the effect of labor market conditions, one finds:

a. The counter-cyclicality of hiring costs and of $Q^{N}$ strengthen, once labor market conditions are included. As $\frac{v}{o+n}$ is pro-cyclical and it enters with a negative sign $\left(e_{21}<0\right)$, then in good (bad) times, hiring costs decline (increase), hence the strengthened counter-cyclicality.

b. The pro-cyclicality of investment costs and $Q^{K}$ strengthen when including labor market conditions. As $\frac{v}{o+n}$ is pro-cyclical and it enters with a positive sign $\left(e_{31}>0\right)$, then in good (bad) times investment costs increase (decline), hence strengthening their pro-cyclicality.

\subsection{Summing Up the Mechanism}

The key notion in this paper is the forward-looking aspect of investment and hiring. The results imply the following cyclical patterns: in a boom investment rates rise while hiring rates decline. This is so because the rates move together with their present values. Specifically, in the U.S. data sample 
examined here, the present value of investment was pro-cyclical while that of hiring was counter-cyclical. As the marginal productivity of capital rises in booms and in subsequent quarters, $Q^{K}$ rises and with it the investment rate. By contrast, the hiring rate falls with the decrease in the present value of hiring, as future labor profitability falls. The latter falls due to the fact that while the labor share first falls in a boom (thereby increasing profitability), it subsequently rises for a substantial period of time.

The set-up examined in this paper and the mechanism emerging from the empirical estimates emphasize intertemporal aspects. Hence it is not enough to consider just current productivity changes; the concurrent change in future variables is no less important. These results are consistent with the observations and claims of three recent contributions dealing with the cyclical behavior of the labor market, each highlighting intertemporal issues that previously were not given much attention:

Hall (2009) models workers' compensation, and consequently the firms' share of the match surplus, as the present value of wage payments over the duration of the job less an hypothetical up-front payment that the worker pays the employer at the beginning of the job, essentially funding hiring costs. Hall thinks of actual compensation arrangements as annuitizing this payment over the duration of the job. Hence in his set-up, as is the case here, there is a distinction between current hiring costs and future profits from labor, which depend on future wage payments.

As noted above, Rios-Rull and Santaeulalia-Llopis (2010) study the behavior of the labor share over time and its cyclical implications. They remark that in RBC models the assumption is that the factor distribution of income is constant at all frequencies. Their findings challenge this premise - there is an overshooting pattern in the U.S. labor share in response to a productivity innovation. They state that "... a productivity innovation produces a reduction in the labor share at impact, making it countercyclical, but it also subsequently produces a long-lasting increase of the labor share that overshoots its long-run average after five quarters and peaks above mean five years later at a level larger in absolute terms than the initial drop, after which it slowly returns to average" (page 931).

Shimer (2010) presents a general equilibrium model with search frictions whereby investment rises when productivity rises but hiring does not change substantially (see, in particular, pages 40 and 75-76). This is so as capital becomes more productive in booms while hiring is influenced by two offsetting effects - booms are times when it is more efficient to produce rather than hire but a decline in interest rates increases the value of hiring. 


\section{Conclusions}

The paper has shown that a model of aggregate investment and hiring with costs capturing frictions is a consistent and reasonable model, which fits U.S. data. It was shown that it is important to examine investment and hiring together, to allow for the interaction between their costs and to allow for dependence on labor market conditions. It is difficult to capture hiring behavior and (even more) investment behavior without considering the other factor. The model fits the data even though costs are estimated to be moderate or small. While hiring and investment decisions have a similar structure, the actual series behave differently. This has to do with the differential behavior of the driving forces, the present values of hiring and of investment and with the differential relations of investment and hiring with the relevant components of these present values. Investment is driven mostly by expected future returns while hiring depends mostly on changes in future labor profitability.

Importantly, in the sample period, the present value of investment $\left(Q^{K}\right)$ behaved pro-cyclically while the present value of hiring $\left(Q^{N}\right)$ behaved countercyclically. These patterns engendered the behavior of investment and hiring described above, including their negative co-movement. In recessions, while employment and the worker job-finding rate declined, the present value of hiring rose, i.e., expected future marginal profitability of labor rose. In these recessionary times, firms, looking into the future, expected higher profitability from employing labor. Hence, they increased the rate at which they hired workers. Relying on the empirical asset-pricing analysis of Section 7 , we know that these expected future gains were related much more to labor profitability than to future discount rates.

This paper, purposefully, did not specify a full DSGE model. This was done in order to focus on firms' investment and hiring decisions and not let the analysis be affected by possible mis-specifications or problematics in other parts of the macroeconomy. To account for firm investment and hiring behavior, one does not need to get into issues such as optimal intertemporal consumption and labor choices of the individual, with all the associated empirical difficulties. Future research may, nonetheless, take up such a model in an attempt to map the linkages between the shocks to the economy and the differential evolution of the relevant present values. 


\section{References}

[1] Abel, Andrew B., 1980. "Empirical Investment Equations: An Integrative Framework," in Brunner, Karl and Allan H. Meltzer (eds.), On the State of Macroeconomics, Volume 12 of the Carnegie-Rochester Conference Series on Public Policy, a Supplementary Series to the Journal of Monetary Economics, 39-91.

[2] Abel, Andrew B., 1983. "Optimal Investment Under Uncertainty," American Economic Review 73:1, 228-233.

[3] Abel, Andrew B. and Janice C. Eberly, 2010. "How Q and Cash Flow Affect Investment without Frictions: An Analytic Explanation," Review of Economic Studies, forthcoming.

[4] Barnichon, Regis, 2010. "Building a Composite Help-Wanted Index," Economics Letters, 109, 3, 175-178.

[5] Bazdresch, Santiago, Frederico Belo and Xiajo Lin, 2009. "Labor Hiring, Investment and Stock Return Predictablity in the Cross Section," working paper.

[6] Bloom, Nicholas, 2009. "The Impact of Uncertainty Shocks," Econometrica $77,3,623-685$.

[7] Bond, Stephen and John Van Reenen, 2007. "Microeconometric Models of Investment and Employment," in J. J. Heckman and E.E. Leamer (eds.) Handbook of Econometrics, Volume 6, Part 1, 4417-4498.

[8] Brainard, William and James Tobin, 1968. "Pitfalls in Financial Model Building," American Economic Review 58,2, 99-122.

[9] Campbell, John .Y., and Robert J. Shiller, 1988. "The Dividend-Price Ratio and Expectations of Future Dividends and Discount Factors," Review of Financial Studies 1, 195-227.

[10] Chirinko, Robert S. 1993. "Business Fixed Investment Spending: Modeling Strategies, Empirical Results, and Policy Implications," Journal of Economic Literature XXXI:1875-1911.

[11] Christiano, Lawrence J., Martin. Eichenbaum, and Charles L. Evans. 2005. "Nominal Rigidities and the Dynamic Effects of a Shock to Monetary Policy." Journal of Political Economy, 113(1): 1-45.

[12] Cochrane, John H., 1991. "Production-Based Asset Pricing and the Link Between Stock Returns and Economic Fluctuations," Journal of Finance, 46, 207-234. 
[13] Cochrane, John H., 1996. "A Cross-Sectional Test of an InvestmentBased Asset Pricing Model," Journal of Political Economy, 104, $572-621$.

[14] Cochrane, John H. 2005. Asset Pricing, 2nd edition, Princeton University Press, Princeton NJ.

[15] Cochrane, John H. 2011. "Discount Rates," NBER WP 16972.

[16] Cooper, Russell and John Haltiwanger, 2006. " On the Nature of Capital Adjustment Costs," Review of Economic Studies 73, 611-633.

[17] Cooper, Russell, John C. Haltiwanger, and Jonathan L. Willis, 2010. "Euler-Equation Estimation for Discrete Choice Models: A Capital Accumulation Application” NBER Working Paper No. 15675.

[18] Erickson, Timothy and Toni M. Whited, 2000. "Measurement Error and the Relationship between Investment and q," Journal of Political Economy 108, 1027-57.

[19] Favilukis, Jack and Xiaoji Lin, 2011. "Micro Frictions, Asset Pricing and Aggregate Implications," LSE mimeo.

[20] Frazis, Harley J., Edwin L. Robison, Thomas D. Evans and Martha A. Duff, 2005. "Estimating Gross Flows Consistent with Stocks in the CPS," Monthly Labor Review, September, 3-9.

[21] Gali, Jordi, 2008. Monetary Policy, Inflation and the Business Cycle: An Introduction to the New Keynesian Framework. Princeton University Press, Princeton.

[22] Gali, Jordi, 2010. "Monetary Policy and Unemployment," in B. Friedman and M. Woodford (eds.) Handbook of Monetary Economics, forthcoming.

[23] Gali, Jordi, and Thijs van Rens, 2010. "The Vanishing Procyclicality of Labor Productivity," CREI working paper.

[24] Garibaldi, Pietro and Espen R. Moen, 2009. "Industry Dynamics and Search in the Labor Market," working paper.

[25] Gilchrist, Simon and Charles P. Himmelberg, 1995. "Evidence on the Role of Cash Flow for Investment," Journal of Monetary Economics 36:541-572.

[26] Gilchrist, Simon and Charles P. Himmelberg, 1998. "Investment: Fundamentals and Finance," NBER Macroeconomic Annual 223-262. 
[27] Hagedorn, Marcus, and Iourii Manovskii, 2008. "The Cyclical Behavior of Equilibrium Unemployment and Vacancies Revisited," American Economic Review, 98, 4, 1692-1706.

[28] Hall, Robert E. 2004. "Measuring Factor Adjustment Costs," Quarterly Journal of Economics, August, 119(3), 899-927.

[29] Hall, Robert E., 2007. "How Much Do We Understand about the Modern Recession?" Brookings Papers on Economic Activity 2, 13-28.

[30] Hall, Robert E., 2009. "Reconciling Cyclical Movements in the Marginal Value of Time and the Marginal Product of Labor," Journal of Political Economy, 117, 2, 281-323.

[31] Hamermesh, Daniel S., 1993. Labor Demand, Princeton (Princeton University Press).

[32] Hamermesh, Daniel S and Gerard A. Pfann, 1996. "Adjustment Costs in Factor Demand," Journal of Economic Literature 34,3, 12641292.

[33] Hansen, Lars P. 1982. "Large Sample Properties of Generalized Method of Moments Estimators," Econometrica 50:1029-1054.

[34] Hayashi, Fumio 1982. "Tobin's Marginal q and Average q: A Neoclassical Interpretation," Econometrica 50:213-224.

[35] Hubbard, R.Glenn., Anil K. Kashyap, and Toni .M. Whited 1995. "Internal Finance and Firm Investment," Journal of Money, Credit and Banking 27:683-701.

[36] Jermann, Urban J., 1998. "Asset Pricing in Production Economies," Journal of Monetary Economics 41, 257-275.

[37] Kahn, Aubhik and Julia K. Thomas, 2008. "Idiosyncratic Shocks and the Role of Nonconvexities in Plant and Aggregate Investment Dynamics," Econometrica 76 (2), 395-436.

[38] Koijen, Ralph S.J. and Stijn Van Nieuwerburgh, 2010. "Predictability of Returns and Cash Flows," NBER Working Paper No.16648.

[39] Lettau, Martin and Sydney C. Ludvisgon, 2009. "Measuring and Modeling Variation in the Risk-Return Tradeoff," in Yacine Ait-Sahalia and Lars Peter Hansen (eds.) Handbook of Financial Econometrics, volume 1, chapter 11, 617-690, Elsevier, North Holland.

[40] Liu, Laura Xiaolei, Toni M. Whited, and Lu Zhang, 2009. "InvestmentBased Expected Stock Returns," Journal of Political Economy 117, 1105-1139. 
[41] Merz, Monika and Eran Yashiv, 2007. "Labor and the Market Value of the Firm," American Economic Review, 97, 4, 1419-1431.

[42] Mortensen, Dale T., 1973. "Generalized Costs of Adjustment and Dynamic Factor Demand Theory," Econometrica 41, 4, 657-665.

[43] Mortensen, Dale T. and Eva Nagypal, 2006. "More on Vacancy and Unemployment Fluctuations," working paper.

[44] Mussa, Michael, 1977. "External and Internal Adjustment Costs and the Theory of Aggregate and Firm Investment," Economica 44:174, 163-178.

[45] Nadiri,M. Ishag and Sherwin Rosen, 1969. "Interrelated Factor Demand Functions," American Economic Review 59, 4, Part 1, 457-471.

[46] Pissarides, Christopher A. 2000. Equilibrium Unemployment Theory, 2nd edition, Cambridge, MIT Press.

[47] Rios-Rull, Jose-Victor and Raul Santaeulalia-Llopis, 2010. "Redistributive Shocks and Productivity Shocks," Journal of Monetary Economics 57, 931-948.

[48] Rogerson, Richard, Robert Shimer and Randall Wright, 2005. "Search Theoretic Models of the Labor Market: A Survey," Journal of Economic Literature XLIII, 959-988.

[49] Rogerson, Richard and Robert Shimer, 2011. "Search in Macroeconomic Models of the Labor Market," in O.Ashenfelter and D.Card (eds.) Handbook of Labor Economics Vol 4A, Amsterdam, Elsevier North Holland.

[50] Shapiro, Matthew .D. 1986. "The Dynamic Demand for Capital and Labor," The Quarterly Journal of Economics 101:513-542.

[51] Shimer, Robert, 2005. "The Cyclical Behavior of Equilibrium Unemployment and Vacancies," American Economic Review, 95,1, 2549.

[52] Shimer, Robert, 2010. Labor Markets and Business Cycles. Princeton University Press, Princeton.

[53] Smets, Frank and Raf Wouters, 2007. "Shocks and Frictions in U.S. Business Cycles: a Bayesian DSGE Approach," American Economic Review 97, 3, 586-606.

[54] Summers, Lawrence H. 1981. "Taxation and Corporate Investment: A q-Theory Approach," Brookings Papers on Economic Activity 1:67-127. 
[55] Tobin, James 1969. "A General Equilibrium Approach to Monetary Theory," Journal of Money, Credit, and Banking 1:15-29.

[56] Yashiv, Eran 2007. "Labor Search and Matching in Macroeconomics," European Economic Review 51, 8, 1859-1895, 


\section{Appendix A}

The Cost Function and Its Key Derivatives and Elasticities

\section{The Cost Function}

$$
g(\cdot)=\left[\frac{e_{1}}{\eta_{1}}\left(\frac{i_{t}}{k_{t}}\right)^{\eta_{1}}+\frac{\left(e_{20}+e_{21} \frac{v_{t}}{u_{t}+o_{t}}\right)}{\eta_{2}}\left(\frac{h_{t}}{n_{t}}\right)^{\eta_{2}}+\frac{\left(e_{30}+e_{31} \frac{v_{t}}{u_{t}+o_{t}}\right)}{\eta_{3}}\left(\frac{i_{t}}{k_{t}} \frac{h_{t}}{n_{t}}\right)^{\eta_{3}}\right] f\left(z_{t}, n_{t}, k_{t}\right) .
$$

\section{First Derivatives}

$$
\begin{aligned}
& g_{i_{t}}=\left[e_{1}\left(\frac{i_{t}}{k_{t}}\right)^{\eta_{1}-1}+\left(e_{30}+e_{31} \frac{v_{t}}{u_{t}+o_{t}}\right)\left(\frac{h_{t}}{n_{t}}\right)^{\eta_{3}} \frac{i_{t}}{k_{t}}{ }^{\eta_{3}-1}\right] \frac{f_{t}}{k_{t}} \\
& g_{h_{t}}=\left[\left(e_{20}+e_{21} \frac{v_{t}}{u_{t}+o_{t}}\right)\left(\frac{h_{t}}{n_{t}}\right)^{\eta_{2-1}}+\left(e_{30}+e_{31} \frac{v_{t}}{u_{t}+o_{t}}\right)\left(\frac{i_{t}}{k_{t}}\right)^{\eta_{3}} \frac{h_{t}}{n_{t}}{ }^{\eta_{3}-1}\right] \frac{f_{t}}{n_{t}} \\
& g_{k_{t}}=-\left[e_{1}\left(\frac{i_{t}}{k_{t}}\right)^{\eta_{1}}+\left(e_{30}+e_{31} \frac{v_{t}}{u_{t}+o_{t}}\right)\left(\frac{h_{t}}{n_{t}} \frac{i_{t}}{k_{t}}\right)^{\eta_{3}}\right] \frac{f_{t}}{k_{t}} \\
& +(1-\alpha)\left[\frac{e_{1}}{\eta_{1}}\left(\frac{i_{t}}{k_{t}}\right)^{\eta_{1}}+\frac{\left(e_{20}+e_{21} \frac{v_{t}}{u_{t}+o_{t}}\right)}{\eta_{2}}\left(\frac{h_{t}}{n_{t}}\right)^{\eta_{2}}+\frac{\left(e_{30}+e_{31} \frac{v_{t}}{u_{t}+o_{t}}\right)}{\eta_{3}}\left(\frac{i_{t}}{k_{t}} \frac{h_{t}}{n_{t}}\right)^{\eta_{3}}\right] \frac{f_{t}}{k_{t}} \\
& g_{n_{t}}=-\left[\left(e_{20}+e_{21} \frac{v_{t}}{u_{t}+o_{t}}\right)\left(\frac{h_{t}}{n_{t}}\right)^{\eta_{2}}+\left(e_{30}+e_{31} \frac{v_{t}}{u_{t}+o_{t}}\right)\left(\frac{h_{t}}{n_{t}} \frac{i_{t}}{k_{t}}\right)^{\eta_{3}}\right] \frac{f_{t}}{n_{t}} \\
& +\alpha\left[\frac{e_{1}}{\eta_{1}}\left(\frac{i_{t}}{k_{t}}\right)^{\eta_{1}}+\frac{\left(e_{20}+e_{21} \frac{v_{t}}{u_{t}+o_{t}}\right)}{\eta_{2}}\left(\frac{h_{t}}{n_{t}}\right)^{\eta_{2}}+\frac{\left(e_{30}+e_{31} \frac{v_{t}}{u_{t}+o_{t}}\right)}{\eta_{3}}\left(\frac{i_{t}}{k_{t}} \frac{h_{t}}{n_{t}}\right)^{\eta_{3}}\right] \frac{f_{t}}{n_{t}}
\end{aligned}
$$

\section{Second Derivatives}

$$
g_{i i_{t}}=\underbrace{\left[\begin{array}{c}
e_{1}\left(\eta_{1}-1\right)\left(\frac{i_{t}}{k_{t}}\right)^{\eta_{1}-2} \\
+\left(e_{30}+e_{31} \frac{v_{t}}{u_{t}+o_{t}}\right)\left(\eta_{3}-1\right)\left(\frac{i_{t}}{k_{t}} \frac{h_{t}}{n_{t}}\right)^{\eta_{3}-2}\left(\frac{h_{t}}{n_{t}}\right)^{2}
\end{array}\right]}_{\tilde{g}_{i i}} \frac{f\left(z_{z}, n_{t}, k_{t}\right)}{k_{t}^{2}}
$$




$$
\begin{gathered}
g_{h h_{t}}=\underbrace{\left[\begin{array}{c}
\left(e_{20}+e_{21} \frac{v_{t}}{u_{t}+o_{t}}\right)\left(\eta_{2}-1\right)\left(\frac{h_{t}}{n_{t}}\right)^{\eta_{2}-2} \\
+\left(e_{30}+e_{31} \frac{v_{t}}{u_{t}+o_{t}}\right)\left(\eta_{3}-1\right)\left(\frac{i_{t}}{k_{t}} \frac{h_{t}}{n_{t}}\right)^{\eta_{3}-2}\left(\frac{i_{t}}{k_{t}}\right)^{2}
\end{array}\right]}_{\widetilde{g}_{h h}} \frac{f\left(z_{z}, n_{t}, k_{t}\right)}{n_{t}^{2}} \\
g_{i h_{t}}=g_{h i_{t}}=\underbrace{\left[\left(e_{30}+e_{31} \frac{v_{t}}{u_{t}+o_{t}}\right) \eta_{3}\left(\frac{i_{t}}{k_{t}} \frac{h_{t}}{n_{t}}\right)^{\eta_{3}-1}\right]}_{\widetilde{g}_{i h}} \frac{f\left(z_{z}, n_{t}, k_{t}\right)}{k_{t} n_{t}}
\end{gathered}
$$

\section{Elasticities}

Starting from the F.O.C and differentiating the following is obtained: ${ }^{20}$

$$
\begin{aligned}
& \frac{\partial i_{t}}{\partial Q^{K}} \frac{Q^{K}}{i_{t}}=\frac{\widetilde{g}_{h h}}{\left(1-\tau_{t}\right)\left[\widetilde{g}_{i i} \widetilde{g}_{h h}-\widetilde{g}_{i h} \widetilde{g}_{h i}\right]} \frac{\frac{Q^{K}}{\frac{f_{t}}{k_{t}}}}{\frac{i_{t}}{k_{t}}} \\
& \frac{\partial h_{t}}{\partial Q^{k}} \frac{Q^{K}}{h_{t}}=-\frac{\widetilde{g}_{h i}}{\left(1-\tau_{t}\right)\left[\widetilde{g}_{i i} \widetilde{g}_{h h}-\widetilde{g}_{i h} \widetilde{g}_{h i}\right]} \frac{\frac{Q^{K}}{\frac{f_{t}}{k_{t}}}}{\frac{h_{t}}{n_{t}}} \\
& \frac{\partial h_{t}}{\partial Q^{N}} \frac{Q^{N}}{h_{t}}=\frac{\widetilde{g}_{i i}}{\left(1-\tau_{t}\right)\left[\widetilde{g}_{i i} \widetilde{g}_{h h}-\widetilde{g}_{i h} \widetilde{g}_{h i}\right]} \frac{\frac{Q^{N}}{\frac{f_{t}}{n_{t}}}}{\frac{h_{t}}{n_{t}}} \\
& \frac{\partial i_{t}}{\partial Q^{N}} \frac{Q^{N}}{i_{t}}=-\frac{\widetilde{g}_{i h}}{\left(1-\tau_{t}\right)\left[\widetilde{g}_{i i} \widetilde{g}_{h h}-\widetilde{g}_{i h} \widetilde{g}_{h i}\right]} \frac{\frac{Q^{N}}{\frac{f_{t}}{h_{t}}}}{\frac{i_{t}}{k_{t}}}
\end{aligned}
$$

\footnotetext{
${ }^{20}$ The complete derivation is avaialble upon request.
} 


\section{Appendix B: The Data}

\begin{tabular}{l|l|l} 
variable & symbol & definition \\
\hline \hline GDP & $f$ & gross value added of NFCB \\
GDP deflator & $p^{f}$ & price per unit of gross value added of NFCB \\
wage share & $\frac{w n}{f}$ & numerator: compensation of employees in NFCB \\
discount rate 1 & $r$ & the rate of consumption growth minus 1 \\
discount rate 2 & $r$ & the weighted average cost of capital - see note 1 \\
employment & $n$ & employment in nonfinancial corporate business sector \\
hiring & $h$ & gross hires \\
separation rate & $\psi$ & gross separations divided by employment \\
vacancies & $v$ & adjusted Help Wanted Index \\
investment & $i$ & gross investment in NFCB sector \\
capital stock & $k$ & stock of private nonresidential fixed assets in NFCB sector \\
depreciation & $\delta$ & depreciation of the capital stock \\
price of capital goods & $p^{I}$ & real price of new capital goods
\end{tabular}

\begin{tabular}{|c|c|c|}
\hline variable & symbol & source \\
\hline GDP & $f$ & NIPA accounts, table 1.14 , line 40 \\
\hline GDP deflator & $p^{f}$ & NIPA table 1.15, line 1 \\
\hline wage share & $\frac{w n}{f}$ & NIPA table 1.14 , lines 17 and 20 \\
\hline discount rate 1 & $r$ & COMPLETE \\
\hline discount rate 2 & $r$ & Fed; see note 1 \\
\hline employment & $n$ & CPS; see note 2 \\
\hline hiring & $h$ & CPS; see note 2 \\
\hline separation rate & $\psi$ & CPS; see note 2 \\
\hline vacancies & $v$ & Conference Board; see note 3 \\
\hline investment & $i$ & BEA and Fed Flow of Funds; see note 4 \\
\hline capital stock & $k$ & BEA and Fed Flow of Funds; see note 4 \\
\hline depreciation & $\delta$ & BEA and Fed Flow of Funds; see note 4 \\
\hline price of capital goods & $p^{I}$ & NIPA and U.S. tax foundation; see note 5 \\
\hline
\end{tabular}

\section{Notes:}

1. The discount rate and the discount factor

I use two alternatives for the firms' discount rate $r_{t}$ and the corresponding discount factor $\beta_{t}=\frac{1}{1+r_{t}}$ :

a. The discount rate based on a DSGE model with logarithmic utility $U\left(c_{t}\right)=\ln c_{t}$.

Then in general equilibrium:

$$
U^{\prime}\left(c_{t}\right)=U^{\prime}\left(c_{t+1}\right) \cdot\left(1+r_{t}\right)
$$

Hence: 


$$
\beta_{t}=\frac{c_{t}}{c_{t+1}}
$$

b. Following the weighted average cost of capital approach in corporate finance, the discount rate is a weighted average of the returns to debt, $r_{t}^{b}$, and equity, $r_{t}^{e}$ :

$$
r_{t}=\omega_{t} r_{t}^{b}+\left(1-\omega_{t}\right) r_{t}^{e}
$$

with

$$
\begin{aligned}
r_{t}^{b} & =\left(1-\tau_{t}\right) r_{t}^{C P}-\theta_{t} \\
r_{t}^{e} & =\frac{\widetilde{c f_{t}}}{\widetilde{s}_{t}}+\widetilde{\widehat{s}}_{t}-\theta_{t}
\end{aligned}
$$

where:

(i) $\omega_{t}$ is the share of debt finance. I calculate it on the basis of Level Tables of Flow of Funds accounts (files ltabs.zip). The calculations are as follows:

1. $D=$ Credit market instruments (FL104104005 in the Coded Tables ltabs.zip, table L.102) + Trade payables (FL103170005 in the Coded Tables ltabs.zip, table L.102)

2. $E=$ Market value of equities (FL103164003 in the Coded Tables ltabs.zip, table L.102)

3. Debt share $=D /(D+E)$.

(ii) The definition of $r_{t}^{b}$ reflects the fact that nominal interest payments on debt are tax deductible. $r_{t}^{C P}$ is Moody's seasoned Aaa commercial paper rate (Federal Reserve Board table H15). The tax rate is $\tau$ as discussed below.

(iii) $\theta$ denotes inflation and is measured by the GDP-deflator of $p^{f}$.

(iv) For equity return I use the CRSP Value Weighted NYSE, Nasdaq and Amex nominal ex-dividend returns $\left(\frac{\widetilde{c f}}{\widetilde{s}_{t}}+\widetilde{\widehat{s}}_{t}\right.$ in terms of the model, using tildes to indicate nominal variables) deflated by the inflation rate $\theta$ ).

2. Employment, hiring and separations

As a measure of employment in nonfinancial corporate business sector $(n)$ I take wage and salary workers in non-agricultural industries (series ID LNS12032187) less government workers (series ID LNS12032188), less self-employed workers (series ID LNS12032192), less unpaid family workers (series ID LNS12032193). All series originate from CPS databases. I do not subtract workers in private households (the unadjusted series ID LNU02032190) from the above due to lack of sufficient data on this variable.

To calculate hiring and separation rates for the whole economy I use the series kindly provided by Ofer Cornfeld. This computation first builds the 
flows between $E$ (employment), $U$ (unemployment) and $N$ (not-in-the-laborforce) that correspond to the $E, U, N$ stocks published by CPS. The methodology of adjusting flows to stocks is taken from BLS, and is given in Frazis et al (2005). This methodology, applied by BLS for the period 1990 onward, produces a dataset that appears in http://www.bls.gov/cps/cps_flows.htm. Here the series have been extended back to 1976.

The quarterly separation rate $(\psi)$ and the quarterly hiring rate $(h / n)$ for the whole economy are defined as follows:

$$
\begin{aligned}
\psi & =\frac{E N+E U}{E} \\
h / n & =\frac{N E+U E}{E}
\end{aligned}
$$

where the employment $(E)$ is the quarterly average of the original seasonally adjusted total employment series from BLS (LNS12000000).

3. Vacancies and Market Tightness

In order to compute $\frac{v}{n+o}$ I use:

(i) The vacancies series based on the Conference Board Composite HelpWanted Index that takes into account both printed and web job advertisements, as computed by Barnichon (2010), available at http://sites.google.com/site/regisbarnichon/research.

This index was multiplied by a constant to adjust its mean to the mean of the JOLTS vacancies series over the overlapping sample period (2001Q12007Q4).

(ii)The unemployment and the out of labor force series are the BLS CPS data.

4. Investment, capital and depreciation

The goal here is to construct the quarterly series for real investment flow $i_{t}$, real capital stock $k_{t}$, and depreciation rates $\delta_{t}$. I proceed as follows:

- Construct end-of-year fixed-cost net stock of private nonresidential fixed assets in NFCB sector, $K_{t}$. In order to do this I use the quantity index for net stock of fixed assets in NFCB (FAA table 4.2, line 28, BEA).

- Construct annual fixed-cost depreciation of private nonresidential fixed assets in NFCB sector, $D_{t}$. The chain-type quantity index for depreciation originates from FAA table 4.5, line 28. The current-cost depreciation estimates are given in FAA table 4.4, line 28.

- Calculate the annual fixed-cost investment flow, $I_{t}$ :

$$
I_{t}=K_{t}-K_{t-1}+D_{t}
$$


- Calculate implied annual depreciation rate, $\delta_{a}$ :

$$
\delta_{a}=\frac{I_{t}-\left(K_{t}-K_{t-1}\right)}{K_{t-1}+I_{t} / 2}
$$

- Calculate implied quarterly depreciation rate for each year, $\delta_{q t}$ :

$$
\delta_{q}+\left(1-\delta_{q}\right) \delta_{q}+\left(1-\delta_{q}\right)^{2} \delta_{q}+\left(1-\delta_{q}\right)^{3} \delta_{q}=\delta_{a}
$$

- Take historic-cost quarterly investment in private non-residential fixed assets by NFCB sector from the Flow of Funds accounts, atabs files, series FA105013005).

- Deflate it using the investment price index (the latter is calculated as consumption of fixed capital in domestic NFCB in current dollars (NIPA table 1.14, line 18) divided by consumption of fixed capital in domestic NFCB in chained 2000 dollars (NIPA table 1.14, line 41). This procedure yields the implicit price deflator for depreciation in NFCB. The resulting quarterly series, $i_{t \_} u n a d j$, is thus in real terms.

- Perform Denton's procedure to adjust the quarterly series $i_{t}$ unadj from Federal Flow of Funds accounts to the implied annual series from BEA $I_{t}$, using the depreciation rate $\delta_{q t}$ from above. I use the simplest version of the adjustment procedure, when the discrepancies between the two series are equally spread over the quarters of each year. As a result of adjustment I get the fixed-cost quarterly series $i_{t}$.

- Simulate the quarterly real capital stock series $k_{t}$ starting from $k_{0}\left(k_{0}\right.$ is actually the fixed-cost net stock of fixed assets in the end of 1975, this value is taken from the series $K_{t}$ ), using the quarterly depreciation series $\delta_{q t}$ and investment series $i_{t}$ from above:

$$
k_{t+1}=k_{t} \cdot\left(1-\delta_{q t}\right)+i_{t}
$$

5. Real price of new capital goods

In order to compute the real price of new capital goods, $p^{I}$, I use the price indices for output and for investment goods. Investment in NFCB Inv consists of equipment $E q$ and structures $S t$. I define the time- $t$ price-indices for good $j=I n v, E q, S t$ as $p_{t}^{j}$ and their change between $t-1$ and $t$ by $\Delta p_{t}^{j}, j=I n v, E q, S t$. These price indices are chain-weighted. Thus:

$$
\frac{\Delta p_{t}^{I n v}}{p_{t-1}^{I n v}}=\omega_{t} \frac{\Delta p_{t}^{E q}}{p_{t-1}^{E q}}+\left(1-\omega_{t}\right) \frac{\Delta p_{t}^{S t}}{p_{t-1}^{S t}}
$$


where

$$
\omega_{t}=\frac{\begin{array}{l}
(\text { nominal expenditure share of } E q \text { in } \operatorname{Inv})_{t-1} \\
+(\text { nominal expenditure share of } E q \text { in } \operatorname{Inv})_{t}
\end{array}}{2} .
$$

The weights $\omega_{t}$ are calculated from the NIPA table 1.1.5, lines 8,10. The price indices $p_{t}^{j}$ for $j=E q, S t$ are from NIPA table 1.1.4, lines 9, 10. I divide the series by the price index for output, $p_{t}^{f}$, to obtain the real price of new capital goods, $p^{I}$.

Note that the price indices $p^{E q}$ and $p^{S t}$ and therefore $p^{I}$ are actually adjusted for taxes. The parameter $\tau$ denotes the statutory corporate income tax rate as reported by the U.S. Tax Foundation.

Let $I T C$ denote the investment tax credit on equipment and public utility structures, $Z P D E$ the present discounted value of capital depreciation allowances, and $\chi$ the percentage of the cost of equipment that cannot be depreciated if the firm takes the investment tax credit. Flint Brayton has kindly provided me with the data. Then

$$
\begin{aligned}
p^{E q}=\widetilde{p}^{E q}\left(1-\tau_{E q}\right) \\
p^{S t}=\widetilde{p}^{S t}\left(1-\tau_{S t}\right), \\
1-\tau^{S t}=\frac{\left(1-\tau Z P D E^{S t}\right)}{1-\tau} \\
1-\tau^{E q}=\frac{1-I T C-\tau Z P D E^{E q}(1-\chi I T C)}{1-\tau}
\end{aligned}
$$




\section{Appendix C \\ Alternative Specifications}

As mentioned in the text, I test for alternative specifications. These are reported in Table $\mathrm{C}-1$.

\section{Table C-1}

The top row gives the preferred benchmark specification of Table 4a, row 6.

The first three rows report other values of fixed powers; they look at higher convexity or allow for quadratic interaction. The problems with these specifications are that they do not fulfill all the conditions for convexity, usually failing the condition on second derivatives, and they imply high marginal investment costs.

The next row reports estimation using constant $\delta$ and $\psi$, set at their sample averages. This yields an insignificant $e_{1}$ estimate and negative marginal costs of investment. Fixing one of these variables only either results in the same outcome or violates the condition on second derivatives for convexity.

Using the weighted average cost of capital (wacc) for $\beta_{t}$ - reported in rows 5, 6, 7 and 8 - results in either high marginal costs of investment or an estimate of the interaction $g_{i h}$ which switches signs over the sample period. Also, in some specifications total and marginal costs switch signs over the sample period. In addition, the condition on second derivatives for convexity is violated.

Using a small instrument set results in a low p-value and some insignificant estimates. Using a large instrument set is fine though some sets violate the conditions on second derivatives for convexity. 
Table 1

Stochastic Behavior of Hiring and Investment logged, HP-filtered and BP-filtered

a. Investment and Hiring Co-Movement $\rho\left(\frac{h_{t}}{n_{t}}, \frac{i_{t+i}}{k_{t+i}}\right)$

HP filtered $(\lambda=1600)$

\begin{tabular}{cccccccc}
$\mathrm{lag} / \mathrm{lead}$ & -8 & -4 & -1 & 0 & 1 & 4 & 8 \\
\hline \hline & -0.06 & -0.06 & -0.19 & -0.16 & -0.16 & 0.01 & 0.11
\end{tabular}

BP filtered (Baxter-King, 6-32)

\begin{tabular}{cccccccc}
$\mathrm{lag} / \mathrm{lead}$ & -8 & -4 & -1 & 0 & 1 & 4 & 8 \\
\hline \hline & -0.09 & -0.04 & -0.27 & -0.29 & -0.25 & 0.03 & 0.18
\end{tabular}

b. Hiring Cyclicality $\rho\left(\frac{h_{t}}{n_{t}}, y_{t+i}\right)$

HP filtered $(\lambda=1600)$

\begin{tabular}{cccccccc}
$\mathrm{lag} / \mathrm{lead}$ & -8 & -4 & -1 & 0 & 1 & 4 & 8 \\
\hline \hline$f$ & -0.08 & -0.12 & -0.28 & -0.21 & -0.17 & -0.01 & 0.10 \\
$\frac{f}{n}$ & -0.07 & 0.00 & -0.07 & -0.03 & -0.08 & 0.01 & 0.03 \\
$\frac{f}{k}$ & -0.10 & -0.13 & -0.26 & -0.18 & -0.14 & 0.03 & 0.11
\end{tabular}

BP filtered (Baxter-King, 6-32)

\begin{tabular}{cccccccc}
$\mathrm{lag} / \mathrm{lead}$ & -8 & -4 & -1 & 0 & 1 & 4 & 8 \\
\hline \hline$f$ & -0.07 & -0.17 & -0.40 & -0.36 & -0.24 & 0.07 & 0.09 \\
$\frac{f}{n}$ & 0.07 & -0.05 & -0.21 & -0.15 & -0.05 & 0.10 & 0.02 \\
$\frac{f}{k}$ & -0.12 & -0.20 & -0.40 & -0.35 & -0.22 & 0.11 & 0.10
\end{tabular}

c. Investment Cyclicality $\rho\left(\frac{i_{t}}{k_{t}}, y_{t+i}\right)$

HP filtered $(\lambda=1600)$

\begin{tabular}{cccccccc}
$\mathrm{lag} / \mathrm{lead}$ & -8 & -4 & -1 & 0 & 1 & 4 & 8 \\
\hline \hline$f$ & -0.22 & 0.45 & 0.82 & 0.79 & 0.65 & 0.03 & -0.31 \\
$\frac{f}{n}$ & 0.05 & 0.60 & 0.62 & 0.51 & 0.32 & -0.29 & -0.41 \\
$\frac{f}{k}$ & -0.10 & 0.57 & 0.83 & 0.75 & 0.56 & -0.13 & -0.42
\end{tabular}

BP filtered (Baxter-King, 6-32)

\begin{tabular}{cccccccc}
$\mathrm{lag} / \mathrm{lead}$ & -8 & -4 & -1 & 0 & 1 & 4 & 8 \\
\hline \hline$f$ & -0.28 & 0.40 & 0.84 & 0.79 & 0.61 & -0.03 & -0.30 \\
$\frac{f}{n}$ & 0.01 & 0.58 & 0.67 & 0.51 & 0.28 & -0.33 & -0.39 \\
$\frac{f}{k}$ & -0.14 & 0.54 & 0.85 & 0.75 & 0.52 & -0.20 & -0.41
\end{tabular}

Notes:

1. The variable $y$ denotes the cyclical indicator which is $f$ (NFCB GDP), or $\frac{f}{n}$ (labor productivity), or $\frac{f}{k}$ (capital productivity). 
Table 2

Stochastic Behavior of Gross Hiring and Other Labor Market Variables

Co-Movement (contemporaneous) with Cyclical Indicators

logged, HP filtered

\begin{tabular}{cccccc} 
& $n_{t}$ & $\frac{h_{t}}{n_{t}}$ & $\frac{h_{t}}{u_{t}+o_{t}}$ & $\frac{\psi}{\frac{h_{t}}{u_{t}+o_{t}}+\psi}$ & $\frac{\frac{1}{n_{t}}}{P O P_{t}}$ \\
\hline \hline with GDP $f$ & 0.82 & -0.20 & 0.51 & -0.67 & -0.88 \\
with labor productivity $\frac{f}{n}$ & 0.32 & -0.03 & 0.35 & -0.55 & -0.48
\end{tabular}

logged, BP filtered

\begin{tabular}{cccccc} 
& $n_{t}$ & $\frac{h_{t}}{n_{t}}$ & $\frac{h_{t}}{u_{t}+o_{t}}$ & $\frac{\psi}{\frac{h_{t}}{u_{t}+o_{t}}+\psi}$ & $\frac{\frac{1}{n_{t}}}{P O P_{t}}$ \\
\hline \hline with GDP $f$ & 0.83 & -0.36 & 0.69 & -0.80 & -0.88 \\
with labor productivity $\frac{f}{n}$ & 0.36 & -0.15 & 0.44 & -0.72 & -0.50
\end{tabular}


Table 3

Descriptive Sample Statistics

Quarterly, U.S. data 1976-2007

\begin{tabular}{lcc}
\hline \hline Variable & Mean & Standard Deviation \\
\hline$\frac{i}{k}$ & 0.024 & 0.004 \\
\hline$\frac{f}{k}$ & 0.166 & 0.014 \\
\hline$\tau$ & 0.387 & 0.057 \\
\hline$\delta$ & 0.017 & 0.003 \\
\hline \hline$\frac{w n}{f}$ & 0.658 & 0.013 \\
\hline$\frac{h}{n}$ & 0.133 & 0.013 \\
\hline$\frac{v}{u+o}$ & 0.057 & 0.012 \\
\hline$\psi$ & 0.132 & 0.012 \\
\hline$\beta$ & 0.994 & 0.005 \\
\hline
\end{tabular}

Note: The sample size contains 127 quarterly observations from 1976:2 to 2007:4. For data definitions see Appendix B. 
Table $4 \mathbf{a}$

GMM Estimates of the FOC (17) and (18)

\begin{tabular}{|c|c|c|c|c|c|c|c|}
\hline & specification & $e_{1}$ & $e_{20}$ & $e_{21}$ & $e_{30}$ & $e_{31}$ & J-Statistic \\
\hline \multirow[t]{2}{*}{1} & investment costs only & 144.16 & - & - & - & - & 76.05 \\
\hline & & $(2.29)$ & - & - & - & - & $(0.09)$ \\
\hline \multirow[t]{2}{*}{2} & hiring costs only & - & 2.75 & - & - & - & 69.21 \\
\hline & & & $(0.13)$ & - & - & - & $(0.22)$ \\
\hline \multirow[t]{2}{*}{3} & both, no interaction & 121.36 & 0.39 & - & - & - & 77.32 \\
\hline & no market tightness & $(6.12)$ & $(0.21)$ & - & - & - & $(0.07)$ \\
\hline \multirow[t]{2}{*}{4} & both, no interaction & 64.62 & 2.45 & -21.13 & - & - & 79.37 \\
\hline & with market tightness & $(5.24)$ & $(0.26)$ & $(2.69)$ & - & - & $(0.04)$ \\
\hline \multirow[t]{2}{*}{5} & both, with interaction & 50.70 & 2.92 & - & -4.87 & - & 67.80 \\
\hline & no market tightness & $(9.29)$ & $(0.35)$ & - & $(1.43)$ & - & $(0.20)$ \\
\hline 6 & $\begin{array}{l}\text { both, with interaction } \\
\text { with market tightness }\end{array}$ & $\begin{array}{l}39.82 \\
(8.94)\end{array}$ & $\begin{array}{c}4.50 \\
(0.48)\end{array}$ & $\begin{array}{c}-35.62 \\
(5.95)\end{array}$ & $\begin{array}{l}-6.10 \\
(1.65)\end{array}$ & $\begin{array}{l}72.75 \\
(22.57)\end{array}$ & $\begin{array}{c}66.10 \\
(0.19)\end{array}$ \\
\hline
\end{tabular}

\section{Notes:}

1. The table reports point estimates with standard errors in parantheses.

2. The J-statistic is reported with $p$ value in parantheses.

3. $\eta_{1}, \eta_{2}, \eta_{3}$ are fixed at $2,2,1 ; \alpha$ is fixed at 0.68 .

4. The instrument set is: $\frac{h}{n}, \frac{w}{\frac{f}{n}}, \frac{v}{u}$ with 10 lags. 
Table $4 \mathrm{~b}$

Adjustment Costs Implied by the GMM Estimation Results

\begin{tabular}{|c|c|c|c|c|c|c|c|}
\hline & \multirow[t]{2}{*}{ specification } & \multicolumn{2}{|c|}{$\frac{g}{f}$} & \multicolumn{2}{|l|}{$\frac{g_{i}}{\underline{f}}$} & \multicolumn{2}{|c|}{$\frac{g_{h}}{f}$} \\
\hline & & mean & std. & mean & std. & mean & std. \\
\hline 1 & investment costs only & 0.044 & 0.014 & 3.54 & 0.55 & - & - \\
\hline 2 & hiring costs only & 0.024 & 0.004 & - & - & 0.36 & 0.03 \\
\hline 3 & $\begin{array}{l}\text { both, no interaction } \\
\text { no market tightness }\end{array}$ & 0.041 & 0.011 & 2.98 & 0.46 & 0.05 & 0.004 \\
\hline 4 & $\begin{array}{l}\text { both, no interaction } \\
\text { with market tightness }\end{array}$ & 0.031 & 0.005 & 1.59 & 0.25 & 0.16 & 0.04 \\
\hline 5 & $\begin{array}{l}\text { both, with interaction } \\
\text { no market tightness }\end{array}$ & 0.025 & 0.003 & 0.61 & 0.23 & 0.26 & 0.05 \\
\hline 6 & $\begin{array}{l}\text { both, with interaction } \\
\text { with market tightness }\end{array}$ & 0.027 & 0.003 & 0.72 & 0.22 & 0.28 & 0.05 \\
\hline
\end{tabular}

\section{Notes:}

1. Mean and std. refer to sample statistics.

2. The functions were computed using the point estimates in Table 4a. 
Table 5

Estimates of the Marginal Adjustment Costs for Capital

Summary of Key Studies for the U.S. Economy

\begin{tabular}{lllll}
\multicolumn{2}{l}{ Study } & Sample & Mean $\frac{i}{k}$ & Mean $\frac{g_{i}}{\frac{f}{k}}$ \\
\hline \hline 1 & Summers (1981) & BEA, 1932-1978 & 0.13 & $2.5-60.5$ \\
2 & Hyashi (1982) & Corporate, 1953-1976 & 0.14 & 3.2 \\
3 & Shapiro (1986) & Manufacturing, 1955-1980 & 0.08 & 1.33 \\
4 & Hubbard et al (1995) & Compustat, 1976-1987 & $0.20-0.23$ & $0.15-0.45$ \\
5 & Gilchrist and Himmelberg (1995) & Compustat, 1985-1989 & $0.17-0.18$ & $0.50-0.98$ \\
6a & Gilchrist and Himmelberg (1998) & Compustat, 1980-1993 & 0.23 & $0.15-0.21$ \\
6b & & Split Sample & & $0.13-1.1$ \\
7 & Hall (2004) & Industry panel, 1958-1999 & 0.10 & 0.10 \\
8 & Cooper and Haltiwanger (2006) & LRD panel, 1972-1988 & 0.12 & $0.04,0.26$ \\
9 & Cooper et al (2010) & LRD panel, 1972-1988 & 0.12 &
\end{tabular}

\section{Notes:}

1. Investment rates $\frac{i}{k}$ are expressed in annual terms.

2. All studies pertain to annual data except Shapiro (1986) who uses quarterly data.

3. The entries in the last column are expressed in terms of $f / k$, so, they are comparable to the estimated marginal costs reported in Table $4 \mathrm{~b}$. 
Table 6

Asset Pricing Tests

\section{Hiring}

a. Single Forecasting Regressions Results

\begin{tabular}{lcccc} 
& & coefficient & standard error & $\bar{R}^{2}$ \\
\hline \hline dividend growth forecasting $^{1}$ & $b$ & 0.11 & 0.03 & 0.08 \\
4 quarter ahead $^{1}$ & $b$ & 0.48 & 0.07 & 0.28 \\
8 quarter ahead $^{1}$ & $b$ & 1.01 & 0.09 & 0.50 \\
12 quarter ahead $^{1}$ & $b$ & 1.42 & 0.09 & 0.66 \\
16 quarter ahead $^{1}$ & $b$ & 1.62 & 0.08 & 0.78 \\
20 quarter ahead $^{1}$ & $b$ & 1.58 & 0.09 & 0.76 \\
& & & & \\
return forecasting $^{1}$ & $b$ & -0.06 & 0.01 & 0.17 \\
4 quarter ahead $^{1}$ & $b$ & -0.22 & 0.03 & 0.28 \\
q quarter ahead $^{1}$ & $b$ & -0.30 & 0.06 & 0.17 \\
12 quarter ahead $^{1}$ & $b$ & -0.24 & 0.08 & 0.06 \\
16 quarter ahead $^{1}$ & $b$ & -0.10 & 0.10 & 0.0003 \\
20 quarter ahead $^{1}$ & $b$ & 0.09 & 0.10 & -0.002
\end{tabular}

b. VARs

coefficient $\quad$ standard error $\quad \bar{R}^{2}$

\begin{tabular}{ccccc}
\hline \hline restricted, forecasting system $^{2}$ & $\phi$ & 0.95 & 0.02 & 0.87 \\
& $b_{d}$ & 0.12 & 0.02 & 0.08 \\
& $b_{r}$ & -0.07 & 0.02 & 0.16 \\
restricted, complete $\mathrm{VAR}^{3}$ & & & & \\
& $b_{p p}$ & 0.90 & 0.02 & 0.87 \\
& $b_{d d}$ & 0.08 & 0.04 & 0.27 \\
& $b_{r r}$ & 0.45 & 0.11 & 0.11 \\
& $b_{d p}$ & 0.19 & 0.02 & 0.27 \\
& $b_{r p}$ & -0.04 & 0.02 & 0.11
\end{tabular}


c. Variance Decomopsition and Long Run Coefficients ${ }^{4}$

\begin{tabular}{lcccc}
$\mathbf{T}$ & $\mathbf{1 0}$ & $\mathbf{2 0}$ & $\mathbf{3 0}$ & $\mathbf{4 0}$ \\
\hline \hline$\frac{b_{d}}{1-\rho \phi}=b_{d}^{l r}$ & & $0.62(0.09)$ & \\
$\frac{b_{r}}{1-\rho \phi}=b_{r}^{l r}$ & & $-0.37(0.09)$ & \\
$\frac{b_{d p}}{1-\rho b_{p p}}=b_{d}^{l r}$ & & $0.82(0.07)$ & \\
$\frac{b_{r p}}{1-\rho b_{p p}}=b_{r}^{l r}$ & & $-0.17(0.07)$ & \\
$\frac{\operatorname{cov}\left[p_{t}-d_{t}, \sum_{j=0}^{T} \rho^{j-1}\left(d_{t+j+1}-d_{t+j}\right)\right]}{\operatorname{var}^{l r}\left(p_{t}-d_{t}\right)}$ & & & & \\
$\frac{\operatorname{cov}\left[p_{t}-d_{t}, \sum_{j=0}^{T} \rho^{j-1} r_{t+j+1}\right]}{\operatorname{var}\left(p_{t}-d_{t}\right)}$ & 0.71 & 0.75 & 0.77 & 0.78 \\
$\frac{e_{t}}{\operatorname{var}\left(p_{t}-d_{t}\right)}$ & -0.21 & -0.18 & -0.19 & -0.18 \\
& 0.08 & 0.07 & 0.04 & 0.04
\end{tabular}




\section{Investment}

a. Single Forecasting Regressions Results

\begin{tabular}{lcccc} 
& coefficient & standard error & $\bar{R}^{2}$ \\
\hline \hline dividend growth forecasting $^{1}$ & $b$ & 0.01 & 0.01 & -0.002 \\
4 quarter ahead $^{1}$ & $b$ & 0.03 & 0.02 & 0.02 \\
8 quarter ahead $^{1}$ & $b$ & 0.07 & 0.03 & 0.04 \\
12 quarter ahead $^{1}$ & $b$ & 0.10 & 0.03 & 0.07 \\
16 quarter ahead $^{1}$ & $b$ & 0.15 & 0.04 & 0.11 \\
20 quarter ahead $^{1}$ & $b$ & 0.23 & 0.04 & 0.21 \\
return forecasting $^{1}$ & & & & \\
4 quarter ahead $^{1}$ & $b$ & -0.02 & 0.01 & 0.05 \\
8 quarter ahead $^{1}$ & $b$ & -0.10 & 0.02 & 0.16 \\
12 quarter ahead $^{1}$ & $b$ & -0.18 & 0.03 & 0.24 \\
16 quarter ahead $^{1}$ & $b$ & -0.26 & 0.04 & 0.30 \\
20 quarter ahead $^{1}$ & $b$ & -0.31 & 0.04 & 0.32 \\
& $b$ & -0.35 & 0.05 & 0.36
\end{tabular}

b. VARs

\begin{tabular}{llccc} 
& & coefficient & standard error & $\bar{R}^{2}$ \\
\hline \hline restricted, forecasting system & & & & \\
& $\phi$ & 0.998 & 0.006 & 0.995 \\
& $b_{d}$ & 0.007 & 0.006 & -0.002 \\
& $b_{r}$ & -0.024 & 0.006 & 0.045 \\
restricted, complete $\mathrm{VAR}^{3}$ & & & & \\
& $b_{p p}$ & 0.997 & 0.005 & 0.994 \\
& $b_{d d}$ & 0.060 & 0.047 & 0.438 \\
& $b_{r r}$ & 0.343 & 0.043 & -0.071 \\
& $b_{d p}$ & 0.015 & 0.004 & 0.438 \\
& $b_{r p}$ & -0.016 & 0.005 & -0.071
\end{tabular}


c. Variance Decompsition and Long Run Coefficients ${ }^{4}$

\begin{tabular}{lcccc}
$\mathbf{T}$ & $\mathbf{6 0}$ & $\mathbf{6 5}$ & $\mathbf{7 0}$ & $\mathbf{7 5}$ \\
\hline \hline$\frac{b_{d}}{1-\rho \phi}=b_{d}^{l r}$ & & $0.23(0.17)$ & \\
$\frac{b_{r}}{1-\rho \phi}=b_{r}^{l r}$ & & $-0.78(0.17)$ & \\
$\frac{b_{d p}}{1-\rho b_{p p}}=b_{d}^{l r}$ & & $0.47(0.13)$ & \\
$\frac{b_{r p}}{1-\rho b_{p p}}=b_{r}^{l r}$ & & $-0.50(0.13)$ & \\
$\frac{\operatorname{cov}\left[p_{t}-d_{t}, \sum_{j=0}^{T} \rho^{j-1}\left(d_{t+j+1}-d_{t+j}\right)\right]}{\operatorname{var}^{l r}\left(p_{t}-d_{t}\right)}$ & & & & \\
$\frac{\operatorname{cov}\left[p_{t}-d_{t}, \sum_{j=0}^{T} \rho^{j-1} r_{t+j+1}\right]}{\operatorname{var}\left(p_{t}-d_{t}\right)}$ & 0.45 & 0.44 & 0.38 & 0.22 \\
$\frac{e_{t}}{\operatorname{var}\left(p_{t}-d_{t}\right)}$ & -0.35 & -0.40 & -0.50 & -0.66 \\
& 0.20 & 0.16 & 0.12 & 0.12
\end{tabular}




\section{Notes:}

1. Forecasting regressions:

Dividend growth forecasting

$$
d_{t+H}-d_{t}=a+b\left(p_{t}-d_{t}\right)+e_{t}
$$

Return forecasting

$$
r_{t+H}=a+b\left(p_{t}-d_{t}\right)+e_{t}
$$

where:

$$
r_{t+H}=r_{t+1}+r_{t+2}+\ldots+r_{t+H}
$$

The table reports results for $H=1,4,8,12,16,20$.

2. Restricted, forecasting system given by:

$$
\begin{aligned}
\left(p_{t+1}-d_{t+1}\right) & =a+\phi\left(p_{t}-d_{t}\right)+e_{p, t} \\
d_{t+1}-d_{t} & =c+b_{d}\left(p_{t}-d_{t}\right)+e_{d, t} \\
r_{t+1} & =d+b_{r}\left(p_{t}-d_{t}\right)+e_{r, t}
\end{aligned}
$$

The restriction is:

$$
b_{d}-b_{r}=1-\rho \phi
$$

where

$$
\rho=\frac{\frac{P}{D}}{1+\frac{P}{D}}
$$

and $P, D$ are sample average values.

3. Restricted, complete VAR:

Using $z_{t}=\left(\begin{array}{c}p_{t}-d_{t} \\ d_{t}-d_{t-1} \\ r_{t}\end{array}\right)$, with the variables de-meaned

$e_{1}=(1,0,0)$

$e_{2}=(0,1,0)$

$e_{3}=(0,0,1)$

$\underline{\varepsilon}_{t}=\left(\begin{array}{c}\varepsilon_{1_{t}} \\ \varepsilon_{2_{t}} \\ \varepsilon_{3_{t}}\end{array}\right)$

The VAR is:

$$
z_{t+1}=B z_{t}+\underline{\varepsilon}
$$


where:

$$
B=\left(\begin{array}{ccc}
b_{p p} & b_{p d} & b_{p r} \\
b_{d p} & b_{d d} & b_{d r} \\
b_{r p} & b_{r d} & b_{r r}
\end{array}\right)
$$

The restrictions are:

$$
e_{1}(I-\rho B)-\left(e_{2}-e_{3}\right) B=0
$$

4. Variance Decomposition and Long Run Coefficients

a. $b_{d}, b_{r}, \phi, b_{d p}, b_{r p}, b_{p p}$ taken from panel b. Standard errors are computed using the delta method.

b. $T$ varies according to the values indicated in the top row. 
Table 7

Scope and Elasticities Implied by The GMM Estimation Results

\begin{tabular}{|c|c|c|c|c|c|c|}
\hline & specification & scope & $\frac{\partial i_{t}}{\partial Q^{K}} \frac{Q^{K}}{i_{t}}$ & $\frac{\partial i_{t}}{\partial Q^{N}} \frac{Q^{N}}{i_{t}}$ & $\frac{\partial h_{t}}{\partial Q^{k}} \frac{Q^{K}}{h_{t}}$ & $\frac{\partial h_{t}}{\partial Q^{N}} \frac{Q^{N}}{h_{t}}$ \\
\hline 1 & investment costs only & 0 & $\begin{array}{c}4.10 \\
(0.98)\end{array}$ & - & - & - \\
\hline 2 & hiring costs only & 0 & - & - & - & $\begin{array}{c}1.00 \\
(0.00)\end{array}$ \\
\hline 3 & $\begin{array}{l}\text { both, no interaction } \\
\text { no market tightness }\end{array}$ & 0 & $\begin{array}{c}4.68 \\
(1.16)\end{array}$ & - & - & $\begin{array}{c}1.00 \\
(0.00)\end{array}$ \\
\hline 4 & $\begin{array}{l}\text { both, no interaction } \\
\text { with market tightness }\end{array}$ & 0 & $\begin{array}{l}7.91 \\
(2.18)\end{array}$ & - & - & $\begin{array}{c}1.00 \\
(0.00)\end{array}$ \\
\hline 5 & $\begin{array}{c}\text { both, with interaction } \\
\text { no market tightness }\end{array}$ & $\begin{array}{c}0.61 \\
(0.05)\end{array}$ & $\begin{array}{l}11.05 \\
(3.18)\end{array}$ & $\begin{array}{c}0.44 \\
(0.13)\end{array}$ & $\begin{array}{c}3.30 \\
(0.35)\end{array}$ & $\begin{array}{c}0.81 \\
(0.08)\end{array}$ \\
\hline 6 & $\begin{array}{l}\text { both, with interaction } \\
\text { with market tightness }\end{array}$ & $\begin{array}{c}0.23 \\
(0.09)\end{array}$ & $\begin{array}{l}12.54 \\
(3.67)\end{array}$ & $\begin{array}{c}0.25 \\
(0.14)\end{array}$ & $\begin{array}{c}1.69 \\
(0.54)\end{array}$ & $\begin{array}{c}0.89 \\
(0.04)\end{array}$ \\
\hline
\end{tabular}

\section{Notes:}

1. All computations are based on the point estimates of Table 4a.

2. The scope statistic is defined as

$$
\frac{g\left(0, \frac{h}{n}\right)+g\left(\frac{i}{k}, 0\right)-g\left(\frac{i}{k}, \frac{h}{n}\right)}{g\left(\frac{i}{k}, \frac{h}{n}\right)}
$$

3. The elasticities are derived in Appendix A. 
Table 8

\section{Cyclical Behavior}

\section{Co-Movement of Investment and Hiring Rates and Their Present Values}

Table 4a, Row 6 specification

\begin{tabular}{cccccccc} 
& \multicolumn{7}{c}{ logged, HP filtered } \\
lag/lead & -8 & -4 & -1 & 0 & 1 & 4 & 8 \\
\hline \hline$\rho\left(\frac{h_{t}}{n_{t}}, \frac{i_{t+j}}{k_{t+j}}\right)$ & -0.06 & 0.01 & -0.11 & -0.10 & -0.11 & 0.03 & 0.07 \\
$\rho\left(Q_{t}^{N}, Q_{t+j}^{K}\right)$ & 0.13 & -0.35 & -0.81 & -0.86 & -0.78 & -0.24 & 0.25 \\
& & & & & & & \\
$\rho\left(\frac{i_{t}}{k_{t}}, Q_{t+j}^{K}\right)$ & -0.35 & 0.33 & 0.84 & 0.83 & 0.69 & 0.02 & -0.31 \\
$\rho\left(\frac{h_{t}}{n_{t}}, Q_{t+j}^{N}\right)$ & 0.11 & 0.05 & 0.20 & 0.41 & 0.05 & -0.06 & -0.13
\end{tabular}

\begin{tabular}{cccccccc}
\multicolumn{7}{c}{ logged, BP filtered } \\
lag/lead & -8 & -4 & -1 & 0 & 1 & 4 & 8 \\
\hline \hline$\rho\left(\frac{h_{t}}{n_{t}}, \frac{i_{t+j}}{k_{t+j}}\right)$ & -0.10 & -0.03 & -0.20 & -0.22 & -0.20 & 0.03 & 0.16 \\
$\rho\left(Q_{t}^{N}, Q_{t+j}^{K}\right)$ & 0.26 & -0.31 & -0.84 & -0.90 & -0.87 & -0.35 & 0.25 \\
& & & & & & & \\
$\rho\left(\frac{i_{t}}{k_{t}}, Q_{t+j}^{K}\right)$ & -0.37 & 0.36 & 0.87 & 0.85 & 0.71 & 0.02 & -0.33 \\
$\rho\left(\frac{h_{t}}{n_{t}}, Q_{t+j}^{N}\right)$ & 0.24 & 0.21 & 0.40 & 0.38 & 0.28 & -0.12 & -0.12
\end{tabular}


II Co-Movement of Series with Business Sector GDP $f$

$$
\rho\left(x_{t}, f_{t+j}\right)
$$

\section{a. Investment costs only}

logged, HP filtered

\begin{tabular}{cccccccc}
$\mathrm{lag} / \mathrm{lead}$ & -8 & -4 & -1 & 0 & 1 & 4 & 8 \\
\hline \hline$\frac{i}{k}$ & -0.25 & 0.41 & 0.82 & 0.76 & 0.60 & 0.02 & -0.25 \\
$\frac{g_{i}}{f / k}$ & -0.25 & 0.41 & 0.82 & 0.76 & 0.60 & 0.02 & -0.25 \\
$Q^{K}$ & -0.19 & 0.36 & 0.82 & 0.79 & 0.67 & 0.10 & -0.27
\end{tabular}

\begin{tabular}{cccccccc}
\multicolumn{7}{c}{ logged, BP filtered } \\
lag/lead & -8 & -4 & -1 & 0 & 1 & 4 & 8 \\
\hline \hline$\frac{i}{k}$ & -0.32 & 0.45 & 0.85 & 0.79 & 0.63 & 0.02 & -0.29 \\
$\frac{g_{i}}{f / k}$ & -0.32 & 0.45 & 0.85 & 0.79 & 0.63 & 0.02 & -0.29 \\
$Q^{K}$ & -0.27 & 0.37 & 0.84 & 0.83 & 0.72 & 0.14 & -0.31
\end{tabular}

\section{b. Hiring costs only}

\begin{tabular}{cccccccc}
\multicolumn{7}{c}{ logged, HP filtered } \\
$\mathrm{lag} /$ lead & -8 & -4 & -1 & 0 & 1 & 4 & 8 \\
\hline \hline$\frac{h}{n}$ & -0.06 & -0.04 & -0.21 & -0.15 & -0.14 & -0.03 & 0.04 \\
$\frac{g h}{f / n}$ & -0.06 & -0.04 & -0.21 & -0.15 & -0.14 & -0.03 & 0.04 \\
$Q^{N}$ & 0.04 & -0.09 & -0.13 & -0.04 & 0.02 & 0.11 & -0.02
\end{tabular}

logged, BP filtered

\begin{tabular}{cccccccc} 
lag/lead & -8 & -4 & -1 & 0 & 1 & 4 & 8 \\
\hline \hline$\frac{h}{n}$ & -0.06 & -0.20 & -0.36 & -0.32 & -0.23 & 0.003 & 0.05 \\
$\frac{g h}{f / n}$ & -0.06 & -0.20 & -0.36 & -0.32 & -0.23 & 0.003 & 0.05 \\
$Q^{N}$ & 0.08 & -0.28 & -0.22 & -0.09 & 0.06 & 0.25 & -0.01
\end{tabular}


c. Both hiring costs and investment costs with interaction, without market tighness

\begin{tabular}{|c|c|c|c|c|c|c|c|}
\hline \multicolumn{8}{|c|}{ logged, HP filtered } \\
\hline lag/lead & -8 & -4 & -1 & 0 & 1 & 4 & 8 \\
\hline$\frac{i}{k}$ & -0.25 & 0.41 & 0.82 & 0.76 & 0.60 & 0.02 & -0.25 \\
\hline$\frac{\stackrel{g}{i}_{i}}{f / k}$ & -0.25 & 0.41 & 0.80 & 0.72 & 0.56 & -0.05 & -0.27 \\
\hline$Q^{K}$ & -0.24 & 0.34 & 0.82 & 0.75 & 0.59 & -0.02 & -0.29 \\
\hline$\frac{h}{n}$ & -0.06 & -0.04 & -0.21 & -0.15 & -0.14 & -0.03 & 0.04 \\
\hline$\frac{g_{h}^{n}}{f / n}$ & 0.04 & -0.26 & -0.58 & -0.51 & -0.44 & -0.07 & 0.14 \\
\hline$Q^{N}$ & 0.09 & -0.27 & -0.51 & -0.42 & -0.32 & 0.01 & 0.10 \\
\hline \multicolumn{8}{|c|}{ logged, BP filtered } \\
\hline lag/lead & -8 & -4 & -1 & 0 & 1 & 4 & 8 \\
\hline$\frac{i}{k}$ & -0.32 & 0.45 & 0.85 & 0.79 & 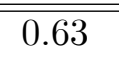 & 0.02 & $\overline{-0.29}$ \\
\hline$\frac{g_{i}}{f / k}$ & -0.32 & 0.43 & 0.85 & 0.77 & 0.59 & -0.05 & -0.30 \\
\hline$Q^{K}$ & -0.31 & 0.41 & 0.87 & 0.81 & 0.63 & -0.01 & -0.32 \\
\hline$\frac{h}{n}$ & -0.06 & -0.20 & -0.36 & -0.32 & -0.23 & 0.003 & 0.05 \\
\hline$\frac{g_{h}^{n}}{f / n}$ & 0.15 & -0.41 & -0.76 & -0.71 & -0.57 & -0.06 & 0.20 \\
\hline$Q^{N}$ & 0.18 & -0.44 & -0.64 & -0.54 & -0.37 & 0.09 & 0.14 \\
\hline
\end{tabular}


d. Both hiring costs and investment costs with interaction, with market tighness

\begin{tabular}{|c|c|c|c|c|c|c|c|}
\hline \multicolumn{8}{|c|}{ logged, HP filtered } \\
\hline lag/lead & -8 & -4 & -1 & 0 & 1 & 4 & 8 \\
\hline$\frac{i}{k}$ & -0.25 & 0.41 & 0.82 & 0.76 & 0.60 & 0.02 & -0.25 \\
\hline$\frac{\stackrel{h}{g}_{i}}{f / k}$ & -0.24 & 0.26 & 0.84 & 0.87 & 0.77 & 0.17 & -0.18 \\
\hline$Q^{K}$ & -0.22 & 0.25 & 0.84 & 0.88 & 0.79 & 0.19 & -0.19 \\
\hline$\frac{h}{n}$ & -0.06 & -0.04 & -0.21 & -0.15 & -0.14 & -0.03 & 0.04 \\
\hline$\frac{g_{h}^{h}}{f / n}$ & 0.20 & -0.24 & -0.81 & -0.87 & -0.82 & -0.35 & 0.03 \\
\hline$Q^{N}$ & 0.23 & -0.26 & -0.80 & -0.84 & -0.77 & -0.30 & 0.01 \\
\hline \multicolumn{8}{|c|}{ logged, BP filtered } \\
\hline lag/lead & -8 & -4 & -1 & 0 & 1 & 4 & 8 \\
\hline$\frac{i}{k}$ & -0.32 & 0.45 & 0.85 & 0.79 & 0.63 & 0.02 & -0.29 \\
\hline$\frac{\stackrel{g_{i}}{f}}{f / k}$ & -0.30 & 0.31 & 0.88 & 0.90 & 0.79 & 0.18 & -0.22 \\
\hline$Q^{K}$ & -0.29 & 0.29 & 0.88 & 0.91 & 0.82 & 0.21 & -0.23 \\
\hline$\frac{h}{n}$ & -0.06 & -0.20 & -0.36 & -0.32 & -0.23 & 0.003 & 0.05 \\
\hline$\frac{g_{h}^{h}}{f / n}$ & 0.28 & -0.30 & -0.87 & -0.93 & -0.89 & -0.39 & 0.13 \\
\hline$Q^{N}$ & 0.31 & -0.36 & -0.88 & -0.90 & -0.83 & -0.31 & 0.12 \\
\hline
\end{tabular}

\section{Notes:}

1. All series are based on the point estimates of Table 4a. Panel IIa corresponds to row 1 in Table 4a; Panel IIb to row 2; Panel IIc to row 5 and panel IId to row 6 .

2. $\frac{Q^{K}}{f / k}$ is net of $p^{I}$. 
Table C-1

Alternative GMM Estimates of the FOC (17) and (18)

\begin{tabular}{|c|c|c|c|c|c|c|c|}
\hline & specification & $e_{1}$ & $e_{20}$ & $e_{21}$ & $e_{30}$ & $e_{31}$ & J-Stat \\
\hline & $\begin{array}{l}\text { Benchmark } \\
\text { Table 4a Row } 6\end{array}$ & $\begin{array}{l}39.8 \\
(8.9)\end{array}$ & $\begin{array}{l}4.50 \\
(0.48)\end{array}$ & $\begin{array}{l}-35.62 \\
(5.95)\end{array}$ & $\begin{array}{l}-6.10 \\
(1.65)\end{array}$ & $\begin{array}{l}72.75 \\
(22.57)\end{array}$ & $\begin{array}{c}66 \\
(0.2)\end{array}$ \\
\hline 1 & $\begin{array}{l}\eta_{1}=\eta_{2}=3 \\
\eta_{3}=1\end{array}$ & $\begin{array}{l}4,717 \\
(401)\end{array}$ & $\begin{array}{l}1.53 \\
(2.10)\end{array}$ & $\begin{array}{l}-10.93 \\
(40.72)\end{array}$ & $\begin{array}{l}11.94 \\
(1.41)\end{array}$ & $\begin{array}{c}-128.72 \\
(31.11)\end{array}$ & $\begin{array}{c}70 \\
(0.1)\end{array}$ \\
\hline 2 & $\begin{array}{l}\eta_{1}=\eta_{2}=3 \\
\eta_{3}=2\end{array}$ & $\begin{array}{l}2,299 \\
(298)\end{array}$ & $\begin{array}{l}21.10 \\
(3.74)\end{array}$ & $\begin{array}{l}-45.11 \\
(53.95)\end{array}$ & $\begin{array}{l}-708.76 \\
(661.13)\end{array}$ & $\begin{array}{l}-5,711 \\
(8,984)\end{array}$ & $\begin{array}{c}66 \\
(0.2)\end{array}$ \\
\hline 3 & $\begin{array}{l}\eta_{1}=\eta_{2}=4 \\
\eta_{3}=1\end{array}$ & $\begin{array}{l}181,247 \\
(14,269)\end{array}$ & $\begin{array}{l}-2.18 \\
(13.89)\end{array}$ & $\begin{array}{c}173.12 \\
(283.93)\end{array}$ & $\begin{array}{l}16.02 \\
(1.33)\end{array}$ & $\begin{array}{c}-172.34 \\
(29.76)\end{array}$ & $\begin{array}{c}67 \\
(0.2)\end{array}$ \\
\hline 4 & $\delta, \psi$ fixed & $\begin{array}{c}6.12 \\
(12.07)\end{array}$ & $\begin{array}{c}6.03 \\
(0.54)\end{array}$ & $\begin{array}{c}-62.45 \\
(5.96)\end{array}$ & $\begin{array}{l}-7.12 \\
(1.75)\end{array}$ & $\begin{array}{l}156.16 \\
(22.28)\end{array}$ & $\begin{array}{c}62 \\
(0.3)\end{array}$ \\
\hline 5 & $\begin{array}{l}\beta \text { using wacc } \\
\eta_{1}=2, \eta_{2}=2, \eta_{3}=1\end{array}$ & $\begin{array}{l}-253.7 \\
(22.4)\end{array}$ & $\begin{array}{l}12.2 \\
(0.9)\end{array}$ & $\begin{array}{l}-55.4 \\
(14.4)\end{array}$ & $\begin{array}{l}-17.3 \\
(4.4)\end{array}$ & $\begin{array}{l}236.9 \\
(57.6)\end{array}$ & $\begin{array}{c}58 \\
(0.4)\end{array}$ \\
\hline 6 & $\begin{array}{c}\beta \text { using wacc } \\
\eta_{1}=2, \eta_{2}=3, \eta_{3}=2\end{array}$ & $\begin{array}{c}-218.39 \\
(20.09)\end{array}$ & $\begin{array}{l}86.77 \\
(9.00)\end{array}$ & $\begin{array}{l}-410.97 \\
(130.29)\end{array}$ & $\begin{array}{l}-6,462 \\
(1,467)\end{array}$ & $\begin{array}{c}77,985 \\
(19,178)\end{array}$ & $\begin{array}{c}57 \\
(0.5)\end{array}$ \\
\hline 7 & $\begin{array}{l}\beta \text { using wacc } \\
\eta_{1}=3, \eta_{2}=4, \eta_{3}=2\end{array}$ & $\begin{array}{l}8,187 \\
(490)\end{array}$ & $\begin{array}{l}-15.4 \\
(22.2)\end{array}$ & $\begin{array}{l}2,214 \\
(480)\end{array}$ & $\begin{array}{c}-1,031 \\
(596)\end{array}$ & $\begin{array}{c}-69,539 \\
(9,955)\end{array}$ & $\begin{array}{c}55 \\
(0.5)\end{array}$ \\
\hline 8 & $\begin{array}{l}\beta \text { using wacc } \\
\eta_{1}=4, \eta_{2}=3, \eta_{3}=1\end{array}$ & $\begin{array}{c}96,217 \\
(21,656)\end{array}$ & $\begin{array}{c}6.56 \\
(4.04)\end{array}$ & $\begin{array}{l}117.84 \\
(70.33)\end{array}$ & $\begin{array}{l}12.69 \\
(2.75)\end{array}$ & $\begin{array}{c}-199.69 \\
(53.79)\end{array}$ & $\begin{array}{c}63 \\
(0.3)\end{array}$ \\
\hline 9 & $\begin{array}{l}\text { small set } \\
4 \text { lags of } \frac{i}{k}, \frac{h}{n}\end{array}$ & $\begin{array}{l}16.8 \\
(16.9)\end{array}$ & $\begin{array}{c}3.0 \\
(0.9)\end{array}$ & $\begin{array}{l}-26.6 \\
(17.7)\end{array}$ & $\begin{array}{c}4.5 \\
(4.4)\end{array}$ & $\begin{array}{l}-35.6 \\
(63.5)\end{array}$ & $\begin{array}{c}45 \\
(0.00002)\end{array}$ \\
\hline 10 & $\begin{array}{l}\text { large set, } 8 \text { lags of } \\
\frac{i}{k}, \frac{h}{n}, \frac{w n}{f}, \frac{v}{u}, p^{i}, \beta\end{array}$ & $\begin{array}{l}108.6 \\
(4.4)\end{array}$ & $\begin{array}{l}-1.05 \\
(0.19)\end{array}$ & $\begin{array}{l}11.8 \\
(2.6)\end{array}$ & $\begin{array}{c}11.4 \\
(0.69)\end{array}$ & $\begin{array}{c}-136.5 \\
(11.4)\end{array}$ & $\begin{array}{c}90 \\
(0.6)\end{array}$ \\
\hline 11 & $\begin{array}{l}\text { large set, } 6 \text { lags of } \\
\frac{i}{k}, \frac{h}{n}, \frac{w n}{f}, \frac{v}{u}, p^{i}, \beta\end{array}$ & $\begin{array}{l}33.65 \\
(7.95)\end{array}$ & $\begin{array}{c}2.79 \\
(0.27)\end{array}$ & $\begin{array}{c}-16.67 \\
(4.18)\end{array}$ & $\begin{array}{l}-0.91 \\
(1.18)\end{array}$ & $\begin{array}{l}-17.47 \\
(21.08)\end{array}$ & $\begin{array}{c}80 \\
(0.2)\end{array}$ \\
\hline
\end{tabular}




\section{Notes:}

1. The table reports point estimates with standard errors in parantheses.

2. The J-statistic is reported with $p$ value in parantheses.

3. $\alpha$ is fixed at 0.68

4. The instrument set is: $\frac{h}{n}, \frac{w}{\frac{f}{n}}, \frac{v}{u}$ with 10 lags, except for rows 9-11 where it is indicated. 
Figures 1 a-d

\section{Business Cycle Facts}

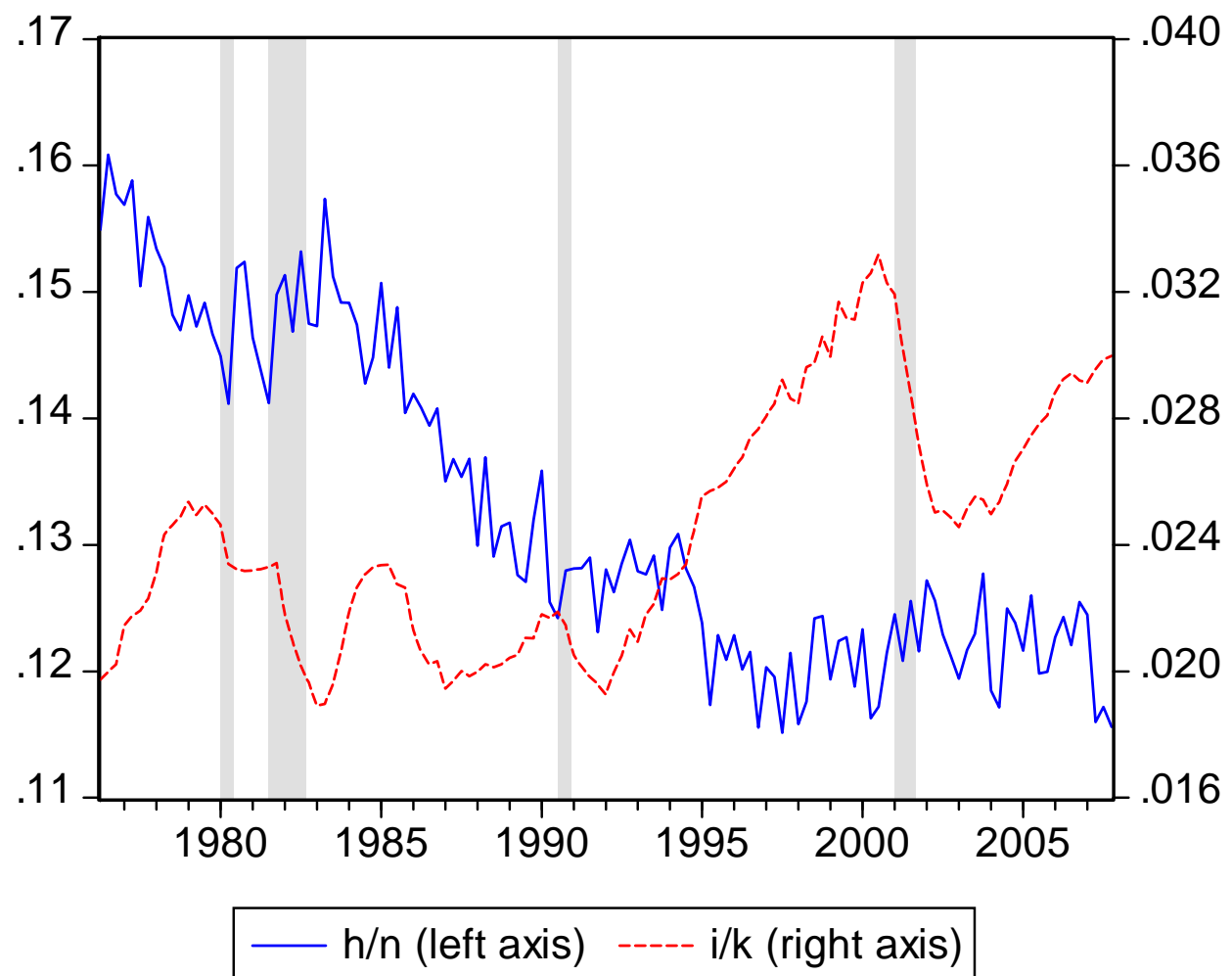

Figure 1a: U.S. hiring $\frac{h}{n}$ and investment $\frac{i}{k}$ rates (raw data) 


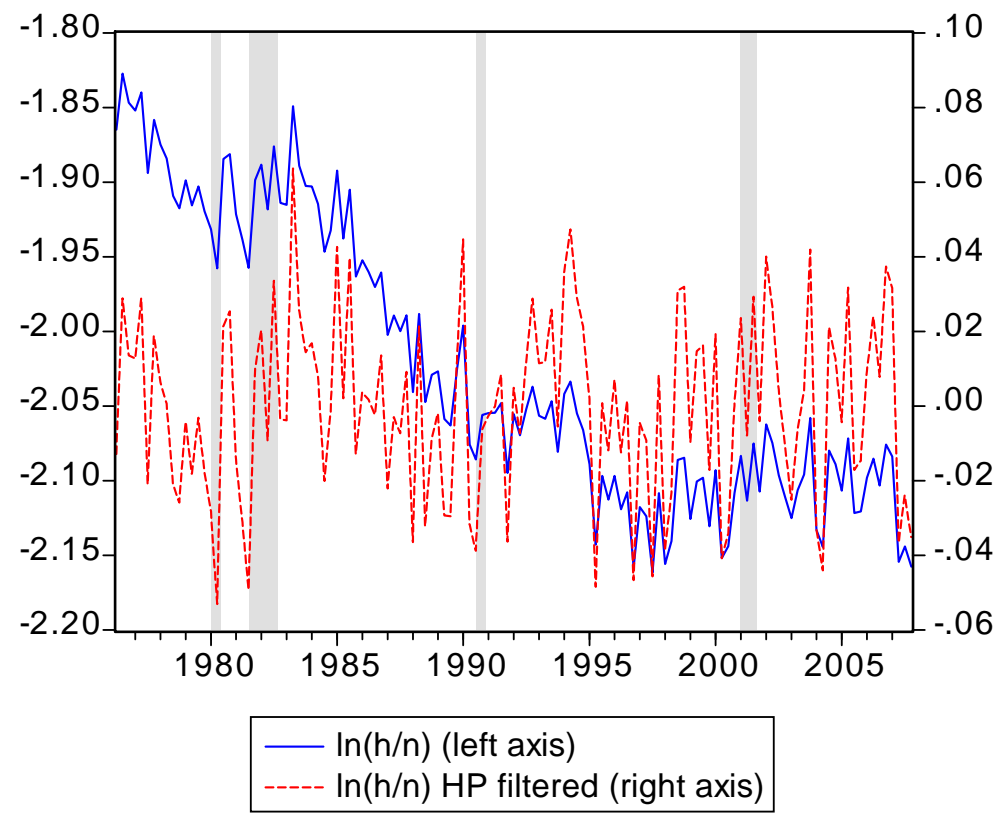

Figure 1b, Panel A: Log Hiring Rates (levels and HP filtered).

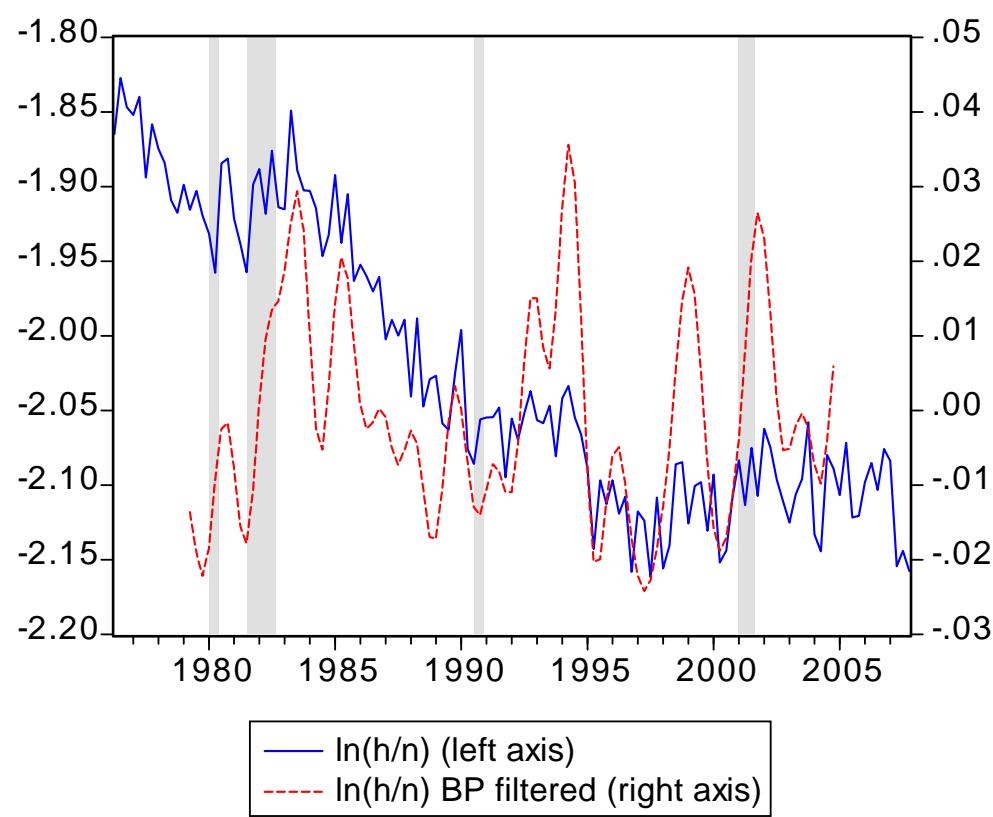

Figure 1b, Panel B: Log Hiring Rates (levels and BP filtered).

xxix 


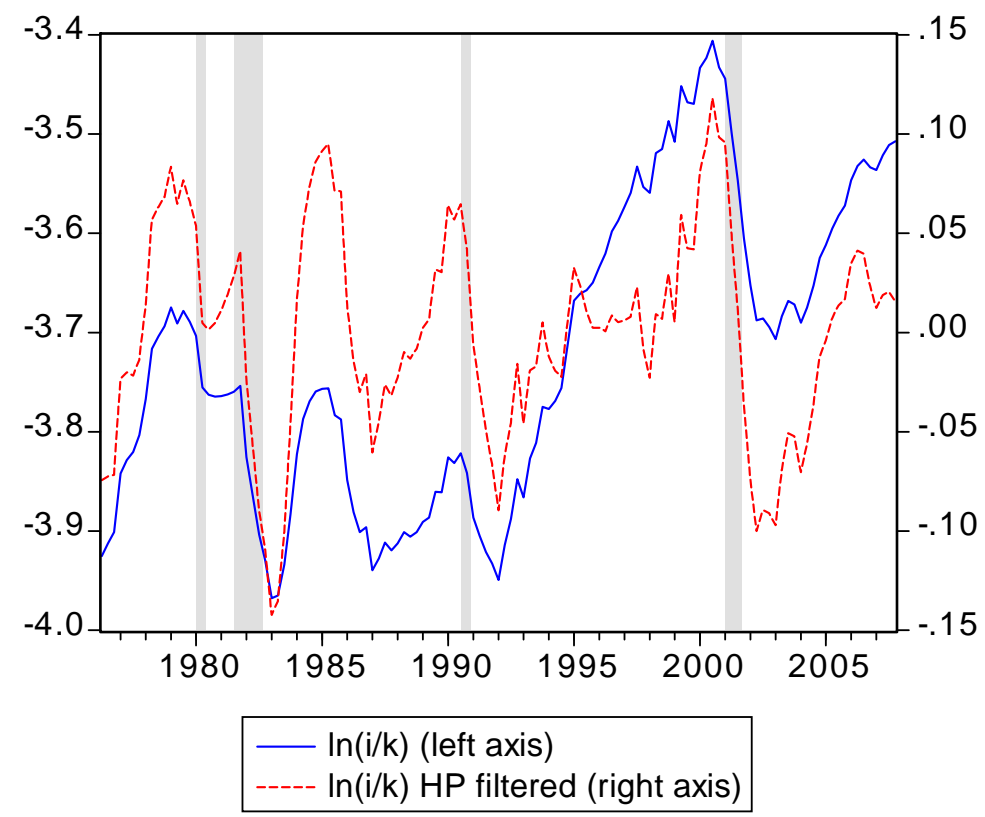

Figure 1c, Panel A: Log Investment Rates (levels and HP filtered).

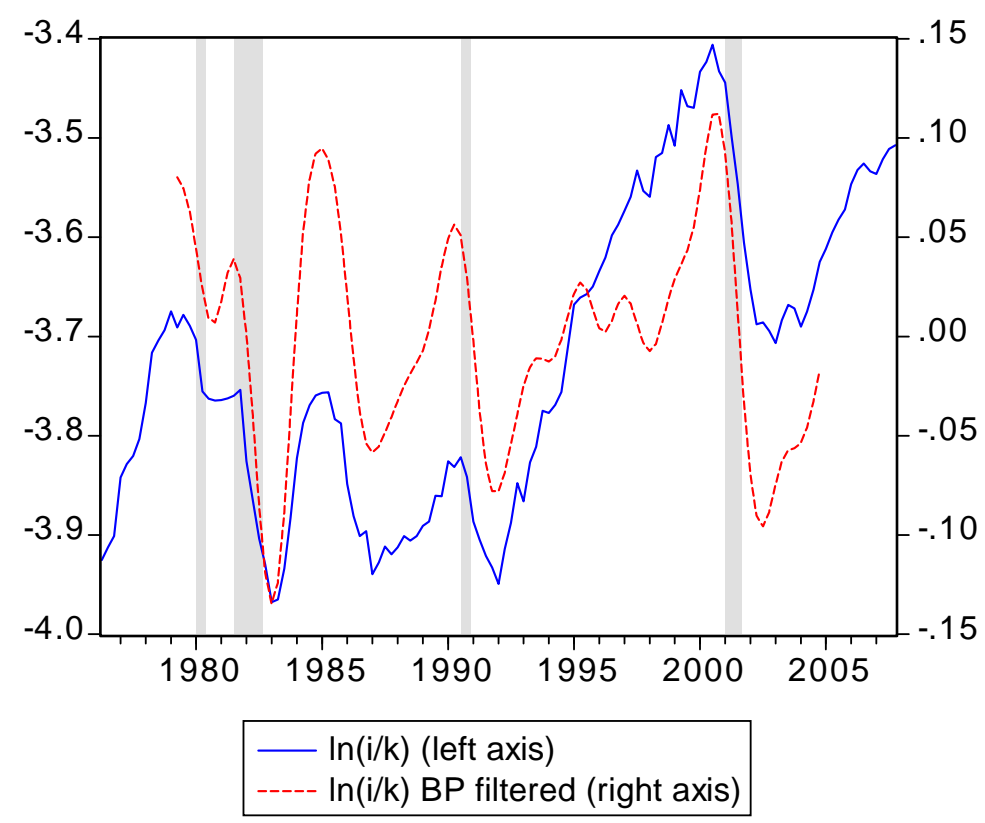

Figure 1c, Panel B: Log Investment Rates (levels and BP filtered). 


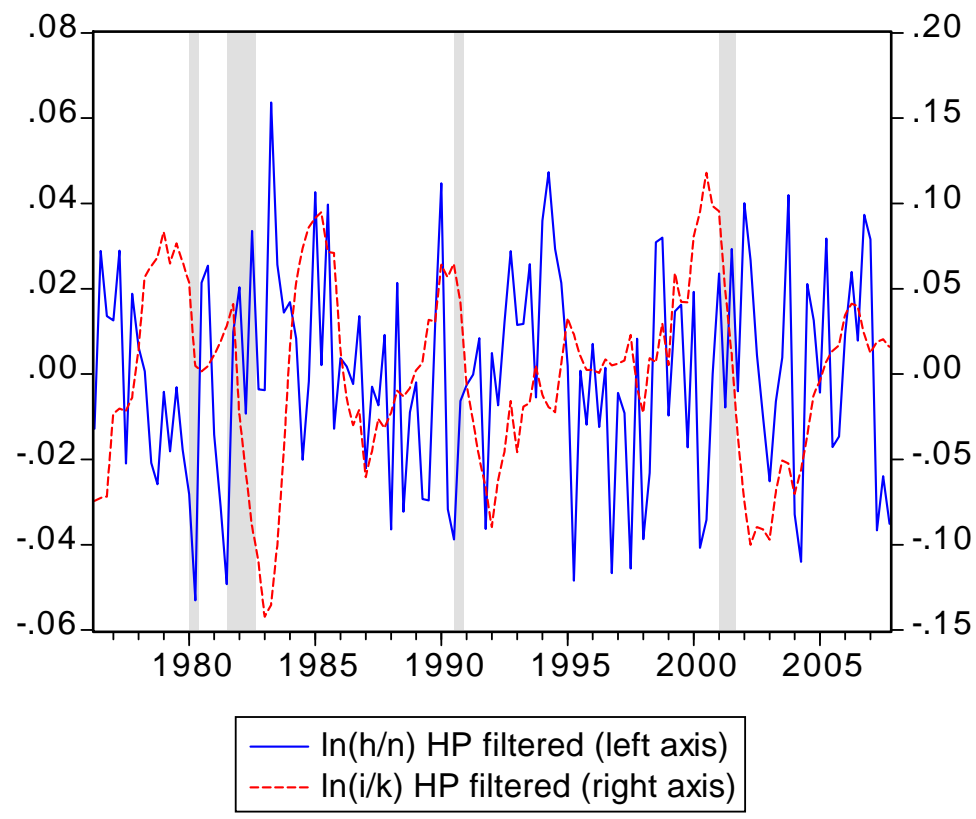

Figure 1d, Panel A: Hiring $\frac{h}{n}$ and investment $\frac{i}{k}$ rates (logged, HP filtered).

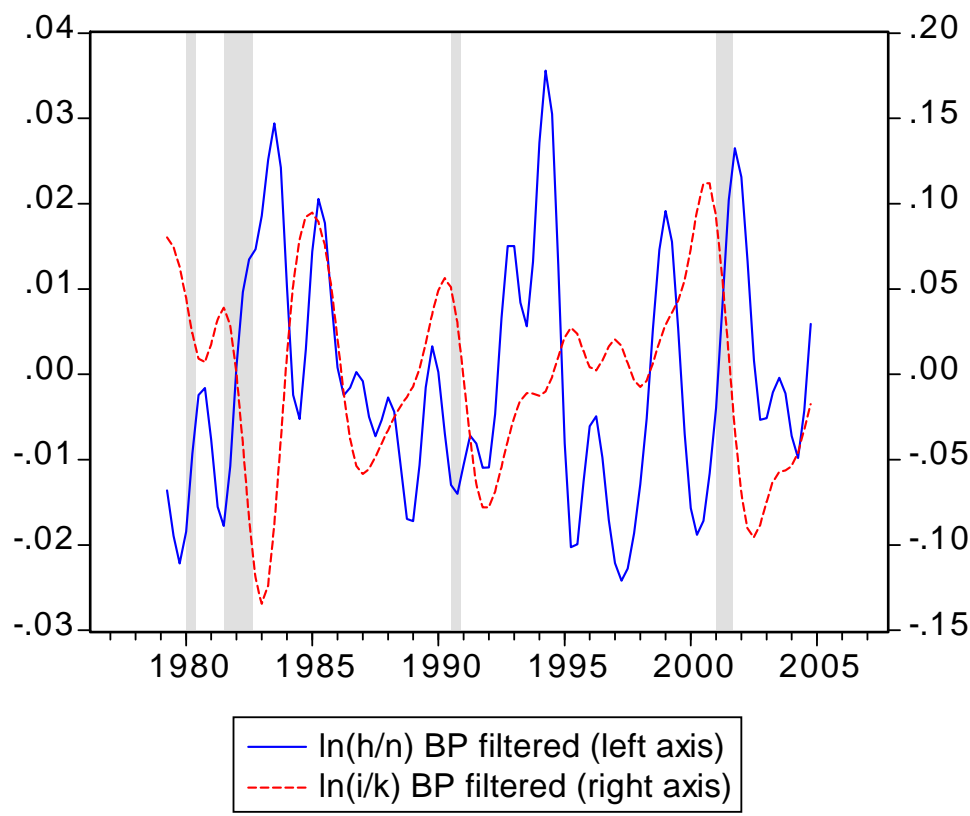

Figure 1d, Panel B: Hiring $\frac{h}{n}$ and investment $\frac{i}{k}$ rates (logged, BP filtered). 
Figure 2

The Estimated Marginal Costs Functions

a. Marginal Investment Costs

$$
\frac{g_{i_{t}}}{\frac{f_{t}}{k_{t}}}=e_{1}\left(\frac{i_{t}}{k_{t}}\right)+\left(e_{30}+e_{31} \overline{\overline{v_{t}}}\right)\left(\overline{\frac{h_{t}}{u_{t}+o_{t}}}\right)
$$

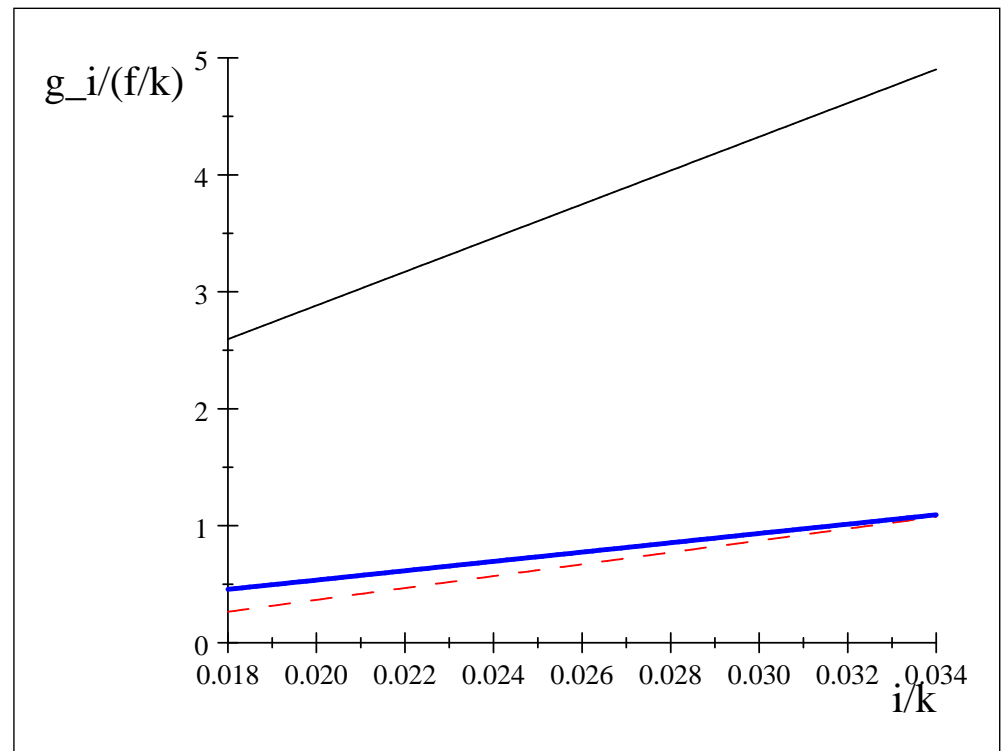

\section{Notes:}

1. The graph uses the point estimates of Table 4 a to plot $\frac{g_{i_{t}}}{\frac{f_{t}}{k_{t}}}$ as a function of $\frac{i_{t}}{k_{t}}$ according to the above equation.

2. The black line uses row 1 estimates - no hiring $e_{30}=e_{31}=0$.

3. The red line (dashed) uses row 5 estimates with interaction but no effect for labor market conditions, $e_{30} \neq 0 ; e_{31}=0$.

4. The blue line (thick, solid) uses row 6 estimates, the full specification $e_{30} \neq 0 ; e_{31} \neq 0$.

5. Throughout average sample values are used for $\overline{\frac{v_{t}}{u_{t}+o_{t}}}$ and for $\frac{\overline{h_{t}}}{n_{t}}$. 


\section{b. Marginal Hiring Costs}

$$
\frac{g_{h_{t}}}{\frac{f_{t}}{n_{t}}}=\left[\left(e_{20}+e_{21} \overline{\frac{v_{t}}{u_{t}+o_{t}}}\right)\left(\frac{h_{t}}{n_{t}}\right)+\left(e_{30}+e_{31} \overline{\overline{v_{t}}}\right)\left(\overline{i_{t}}\right)\right]
$$

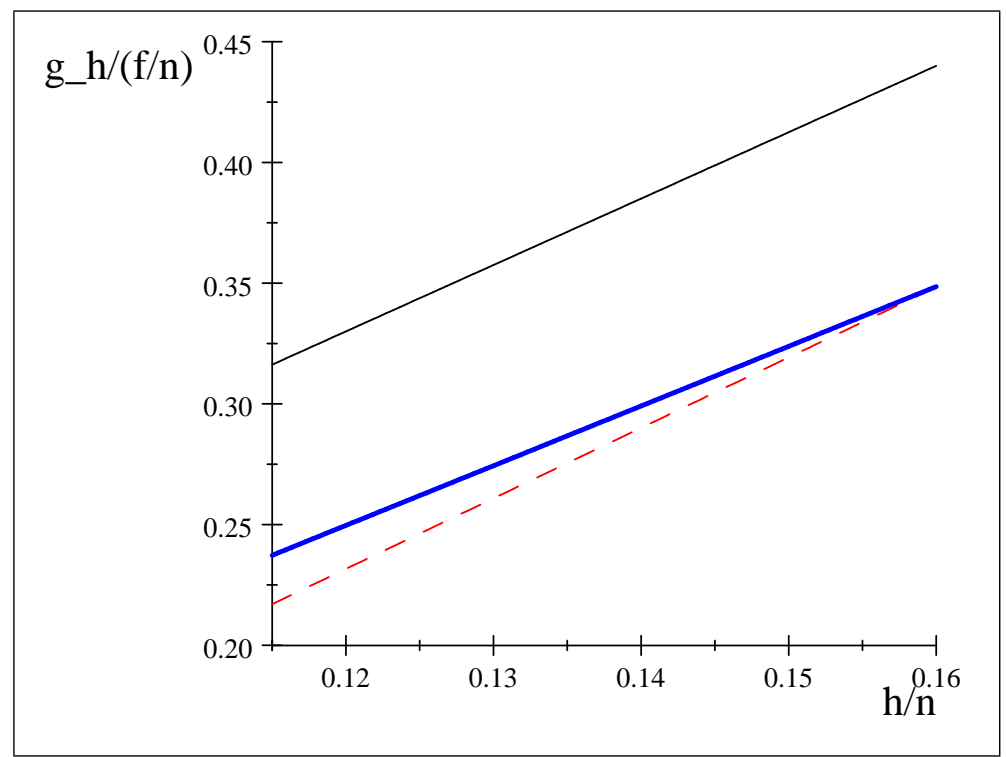

\section{Notes:}

1. The graph uses the point estimates of Table 4 a to plot $\frac{g_{h_{t}}}{\frac{f_{t}}{n_{t}}}$ as a function of $\frac{h_{t}}{n_{t}}$ according to the above equation.

2 . The black line uses row 2 estimates - no investment $e_{30}=e_{31}=0$.

3 . The red line (dashed) uses row 5 estimates with interaction but no effect for labor market conditions, $e_{30} \neq 0 ; e_{31}=0$.

4. The blue line (solid, thick) uses row 6 estimates, the full specification $e_{30} \neq 0 ; e_{31} \neq 0$.

5. Throughout average sample values are used for $\overline{\frac{v_{t}}{u_{t}+o_{t}}}$ and for $\frac{\overline{i_{t}}}{k_{t}}$. 
Figures 3 a-d: Investment and Hiring: Log Levels (filtered), Present Values and GDP
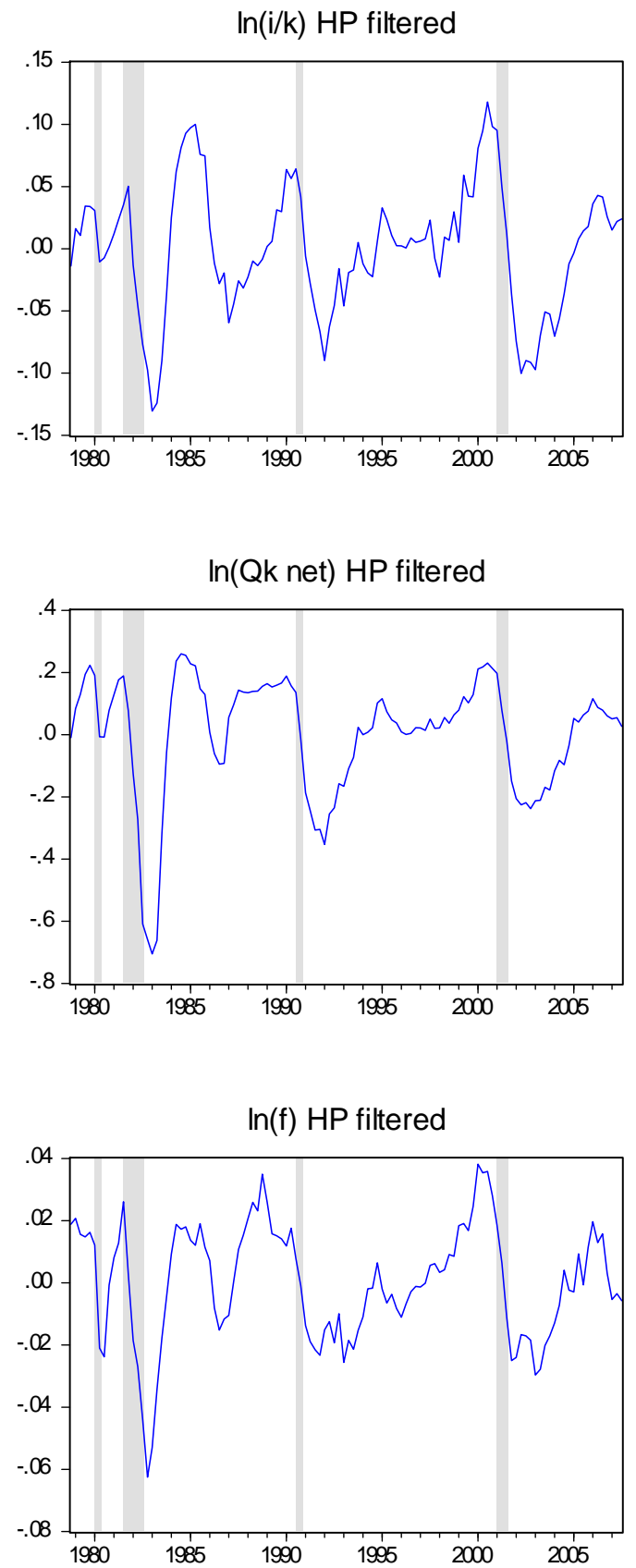

Figure 3a: $\frac{i}{k}, Q^{K}$ (net), $f$ logged, HP filtered. 

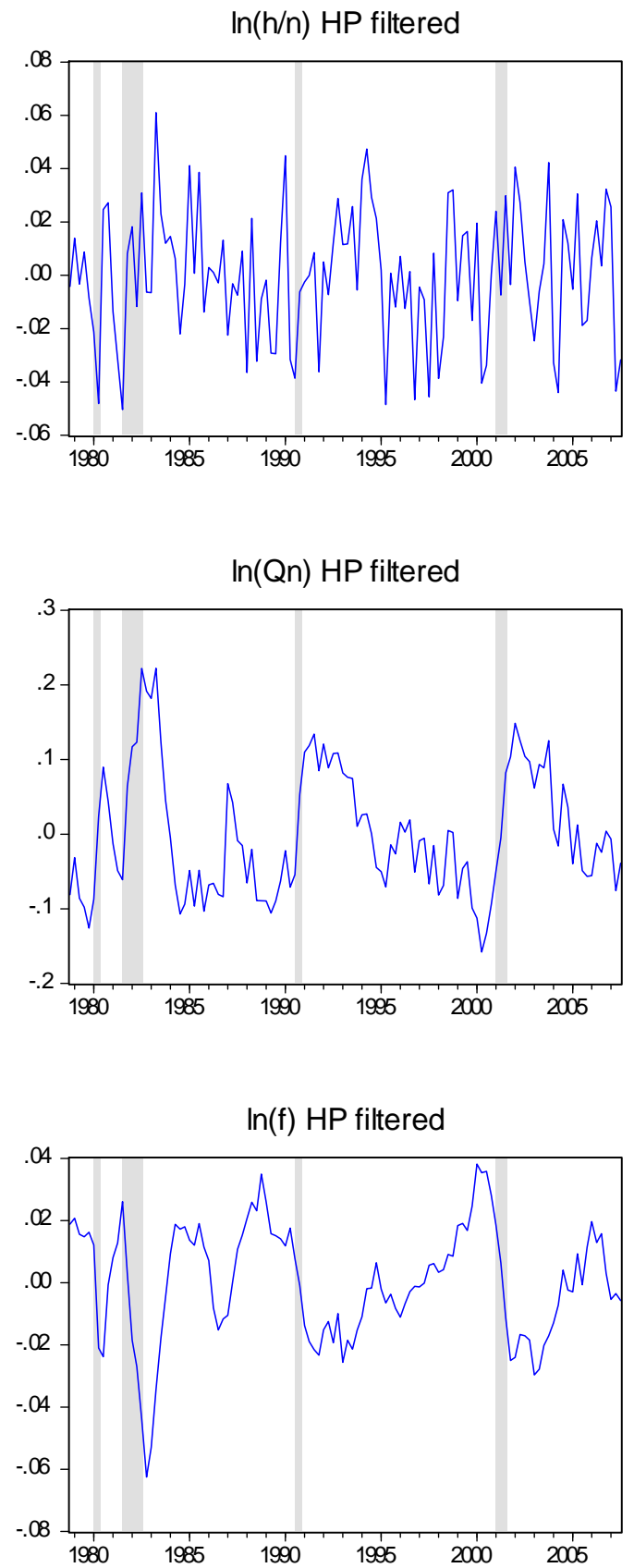

Figure $3 \mathrm{~b}: \frac{h}{n}, Q^{N}, f$ logged, HP filtered. 

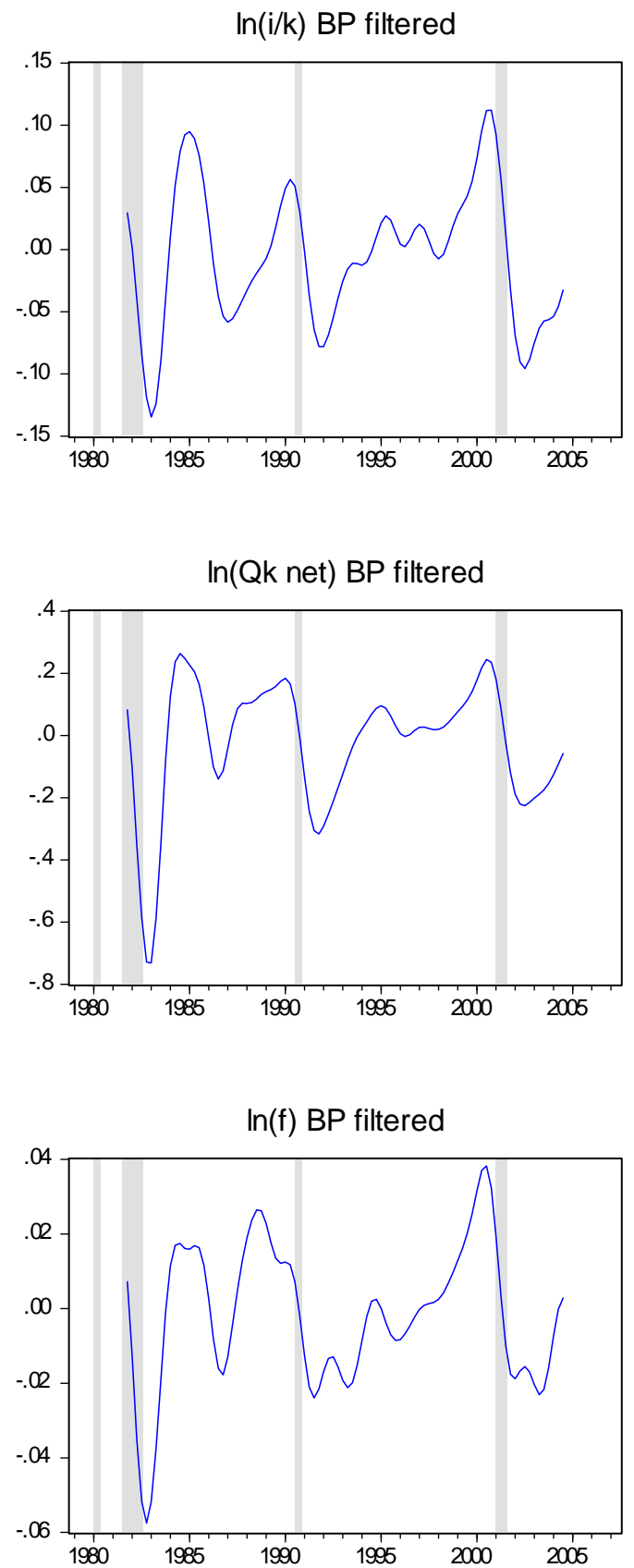

Figure $3 \mathrm{c}: \frac{i}{k}, Q^{K}$ (net), $f$ logged, BP filtered. 

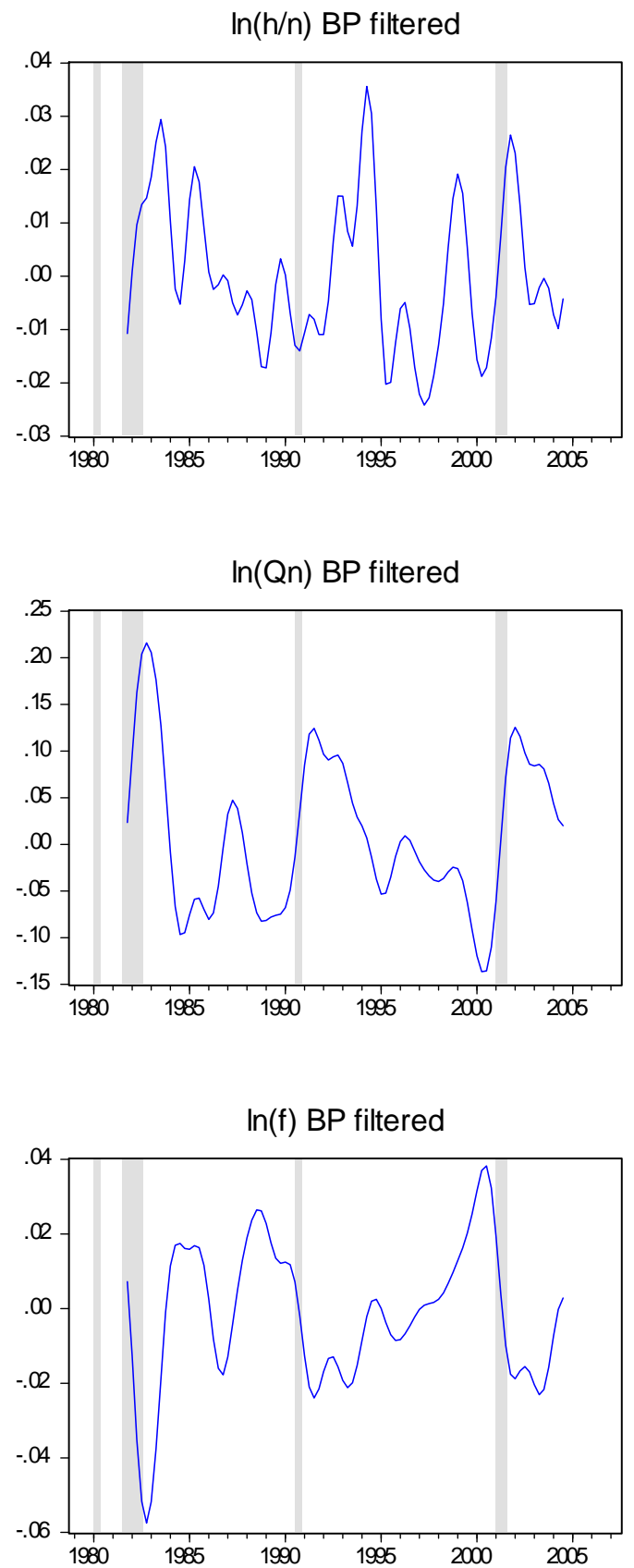

Figure 3d: $\frac{h}{n}, Q^{N}, f$ logged, BP filtered. 